\title{
Dissipation source terms and whitecap statistics
}

\author{
Fabien Leckler $^{a, *}$, Fabrice Ardhuin ${ }^{a}$, Jean-François Filipot ${ }^{b}$, Alexey Mironov ${ }^{a}$ \\ a Laboratoire d'Océanographie Spatiale, Ifremer, 29280 Plouzané, France \\ b Centre Militaire d'Océanographie, Service Hydrographique et Océanographique de la Marine, 29609 Brest, \\ France \\ *: Corresponding author : Fabien Leckler, tel.: +33 632004040x3002 ; fax: +33 298334533 ; \\ email address : fabien.leckler@ifremer.fr
}

\begin{abstract}
:
Whitecaps are the main sink of wave energy and their occurrence has been related to the steepness of the waves. Recent parameterizations of the wave dissipation in numerical models are based on this property, but wave models have seldom been verified in terms of whitecap properties. Here we analyze and adjust the breaking statistics used in two recent wave dissipation parameterizations implemented in the spectral wave model WAVEWATCH III and now used operationaly at NOAA/NCEP. For dominant breaking waves, the reduction of breaking probabilities with wave age is well reproduced. Across the spectrum, the parameterizations produce a reasonable distribution of breaking fronts for wave frequencies up to three times the dominant frequency, but fail to reproduce the observed reduction in breaking front lengths for the shorter waves. Converted to whitecap coverage, the breaking parameterizations agree reasonably well with the classical empirical fits of whitecap coverage against wind speed and the global whitecap coverage estimated from space-borne radiometry.
\end{abstract}

\section{Highlights}

- Breaking parameterizations with different spectral distributions are analyzed. Modeling of whitecap properties is proposed and results are compared to observations. Radiometric remote sensing of whitecap properties is used to verify the model.

Keywords: Wave breaking ; Dissipation source term ; Whitecap statistics

\section{Introduction}

Phase-averaged wave models consider the spectral decomposition of the sea surface elevation across wavenumbers $k$ (or frequencies $f$ ) and directions $\theta$ at point $(x, y)$ and time $t$. The evolution of spectral density $F(k, \theta, x, y, t)$ is resolved using the wave energy balance equation proposed by Gelci et al. (1957):

$\frac{d F}{d t}=S_{\mathrm{atm}}+S_{\mathrm{nl}}+S_{\mathrm{oc}}+S_{\mathrm{bt}}+\cdots$

where the Lagrangian derivative of spectral density on the left-hand side includes the local time evolution and advection in both physical and spectral spaces (e.g. WISE Group, 2007). The source terms on the right-hand side include an atmospheric source term $S_{\text {atm }}$ which includes the classical input of energy $S_{\text {in }}$ from wind to waves, and the energy output $S_{\text {out }}$ from waves to 
wind $^{1}$, associated with friction at air-sea interface (Ardhuin et al., 2009). The nonlinear source term $S_{\mathrm{nl}}$ represents energy transfers in the spectral domain due to wave-wave interactions. $S_{\mathrm{bt}}$ is the sink of energy due to bottom friction. Other effects may also be included (WISE Group, 2007). Finally, the oceanic source term $S_{\text {oc }}$, usually negative, represents dissipation due to wave breaking and wave-turbulence interactions (e.g. Ardhuin and Jenkins, 2006). The latter effect will be ignored here, because it typically represents at most a $10 \%$ fraction of the breaking-induced dissipation (Rascle et al., 2008; Kantha et al., 2009), and here we focus on wave breaking. The goal of the present paper is to evaluate the whitecap properties associated with the parameterization of breaking waves.

Early parameterizations of dissipation were adjusted to close the energy balance of waves, with no explicit link to breaking and dissipation observations. This, in particular, was the basis of the parameterizations of Komen et al. (1984). Following Phillips (1984), it was shown that breaking probabilities could be related to the saturation spectrum $B(k)$. This approach was extended to the parametrization of breaking probabilities for dominant waves (Banner et al., 2000). In particular, it was found that breaking probabilities become significant when the saturation exceeds a constant threshold $B_{\mathrm{r}}$. A similar threshold may also be applied to waves shorter than the dominant waves (Banner et al., 2002).

A preliminary modeling effort based on these observations was made by

\footnotetext{
${ }^{1}$ The transfer of energy from waves to wind $\left(S_{\text {out }}\right)$ is responsible for the swell dissipation over long distances. A modification of the formulation of Ardhuin et al. (2010) is provided in Appendix A.
} 
Alves and Banner (2003) who modified the Komen et al. (1984) dissipation to include a further dependence on the ratio $B(k, \theta) / B_{\mathrm{r}}$. Then, van der Westhuysen et al. (2007) built another parameterization where the dissipation rate is a function of $B(k, \theta) / B_{\mathrm{r}}$ to a power that varies with the wave age. That type of dependency was abandoned by Banner and Morison (2010). Ardhuin et al. (2010) further introduced a directional dependence of the dissipation rate, with much strong dissipation in the mean direction, consistent with observed higher probabilities of breaking waves propagating in the mean direction (Mironov and Dulov, 2008). Conversly, the parameterization by Babanin et al. (2010) assumes a stronger dissipation in oblique directions. More importantly these last three parameterizations also include some suppression of the short wave energy due to the breaking of longer waves. This so-called cumulative effect is consistent with many observations (Banner et al., 1989; Melville et al., 2002; Young and Babanin, 2006).

In his analysis, Phillips (1984) had warned that the use of the saturation spectrum was only meaningful if the spectrum was relatively smooth. Indeed, monochromatic waves of very small amplitude have an infinite saturation level but do not produce any breaking. The saturation-based parameterization of Ardhuin et al. (2010), hereinafter referred to as TEST451², does not use a smoothed saturation spectrum. In practice the wave spectrum is most saturated at the peak of the wind sea. As a result, that parameterization gives an abnormal lower dissipation rate on frequences just above the

\footnotetext{
${ }^{2}$ Compared to the version TEST441b described in that paper, we have introduced a minor swell dissipation modification described in Appendix A. This modification has no impact on the breaking statistics.
} 
peak, that is difficult to reconcile with the relatively broad spectral signature expected from the short lifetime of each breaking event.

For this reason, Banner and Morison (2010) use a smoothed saturation spectrum. A different smoothing procedure is used in the parameterization by Filipot and Ardhuin (2012), hereinafter referred to as TEST500. They defined wave steepnesses for different scales based on a moving-window integration of the spectrum. This parameterization has two benefits. Firstly, it allows the estimation of breaking probabilities for different scales, in a way consistent with observations (Filipot et al., 2010). Secondly, it provides a natural way of combining deep and shallow water breaking in a single formulation, extending the work of Thornton and Guza (1983) and Chawla and Kirby (2002). One inconsistency of TEST500 is that it uses the cumulative effect of Ardhuin et al. (2010) which is based on different breaking probabilities. For this reason we propose here a modification of TEST500, called TEST570.

Mixing air into water, breaking waves form clouds of bubbles beneath the sea surface and foamy patches on the surface. This surface signature makes breaking easily observable with simple visible video or photo camera (Mironov and Dulov, 2008; Thomson and Jessup, 2008; Kleiss and Melville, 2011). The video observations collected at small scales, traditionally from research platforms, ships, or aircraft give information about breaking probability and breaking crest length density as functions of wavenumber (or wave scale). Another source of whitecap measurement is given by the very clear signature of bubbles and foam on the emissivity and brightness of sea surface temperature (Droppleman, 1970). This property was particularly exploited 
by Anguelova and Webster (2006). Using satellite radiometric measurements, they gave the first global dataset of whitecap coverage.

Many investigations have resulted in relationships between the whitecap coverage and the wind speed at $10 \mathrm{~m}$ above the sea surface, $U_{10}$. These relationships exhibit a large variability which cannot be predicted only with the wind speed. Although the measurement conditions, in particular the view geometry and lighting conditions are an inherent source of scatter in video measurements, there are also environmental and meteorological factors besides the wind speed that may explain some of this scatter. These include air-sea temperature difference $\Delta T$, water salinity, but also sea state parameters such as the significant wave height $H_{s}$ or wave age (Monahan and Muircheart, 1981). Indeed, Hanson and Phillips (1999) found that observed wave age explained a large part of the scatter in the whitecap coverage measurements that they analyzed. Recent measurement campaigns have focused on the estimation of the spectral distribution of breaking crest lengths, introduced by Phillips (1985). Banner and Morison (2010) have shown that their parameterization of wave dissipation was indeed able of reproducing the variability in dominant breaking wave crest lengths. In order to investigate the general applicability of our wave model for such a task, we confront here our model to the global radiometric data of Anguelova et al. (2009).

In section 2 we describe the two parameterizations by Ardhuin et al. (2010) and Filipot and Ardhuin (2012), with a minor update to the latter to make the cumulative effect consistent. This updated parameterization is called TEST570. Resulting disspation and breaking crest length density are analized in section 3 with an academic test case. In the next section, we 
interpret whitecap coverage $W$ and mean foam thickness $\bar{\Delta}$ compared to radiometer data over the world ocean. Conclusions and perspectives follow in section 5 .

\section{Dissipation parameterizations and breaking probabilities}

\subsection{Previous parameterization}

Ardhuin et al. (2010) defined ${ }^{3}$ a directional saturation spectrum $B^{\prime}(k, \theta)$, partially integrated over directions between $\theta-\Delta_{\theta}$ and $\theta+\Delta_{\theta}$,

$$
B^{\prime}(k, \theta)=\int_{\theta-\Delta_{\theta}}^{\theta+\Delta_{\theta}} k^{3} \cos ^{2}\left(\theta-\theta^{\prime}\right) F\left(k, \theta^{\prime}\right) \mathrm{d} \theta^{\prime}
$$

with $\Delta_{\theta}=80^{\circ}$. This directional sector of plus or minus $80^{\circ}$, combined with the cosine-square weighting is there to limit the integration of wave trains that actually have enough time to merge together so that individual waves can evolve to breaking (e.g. Banner and Tian, 1998). Because the high frequency gravity waves are generally distributed more broadly over directions, this parameterization also reduces the breaking probability at high frequencies, in a way similar to the directional normalization used by Banner and Morison (2010) or Rogers et al. (2012). Varying $\Delta_{\theta}=80^{\circ}$ from 50 to $120^{\circ}$ has very little influence on the model results. This reduction of breaking probability with directional spreading is also consistent with a smaller whitecap coverage in crossing seas (Holthuijsen et al., 2012), although the physical processes involved may be different.

\footnotetext{
${ }^{3}$ We corrected the typographic error in equation (12) of Ardhuin et al. (2010) by removing the erroneous factor $\mathrm{d} f / \mathrm{d} k=C_{\mathrm{g}} /(2 \pi)$.
} 
The actual estimation of the dissipation induced by spontaneous breaking $S_{\mathrm{bk}, \mathrm{sp}}$ is a weighted average of a dissipation given by the directional saturation $B^{\prime}(k, \theta)$ and an isotropic dissipation given by the usual non-directional saturation spectrum $B(k)$

$$
B(k)=\max \left\{B^{\prime}\left(k, \theta^{\prime}\right), \theta^{\prime} \in[0,2 \pi]\right\} .
$$

This combination of $B^{\prime}(k, \theta)$ and $B(k)$ allowed a control of the dissipation directionality which was adjusted to reproduce observed directional spreadings, and also provided good estimates of the energy levels in opposing wave directions (Ardhuin and Roland, 2012).

For the cumulative dissipation, the breaking probability is estimated from the directional saturation spectrum $B^{\prime}$, extrapolating the empirical expression given by Banner et al. (2000) for dominant waves on the entire spectrum, and assuming that for the dominant waves the steepness is given by $B^{\prime} / 1.6$. This gives a spectral breaking probability $P_{\mathrm{b}}$

$$
P_{\mathrm{b}}(k, \theta)=28.4 \max \left[\sqrt{B^{\prime}(k, \theta)}-\sqrt{B_{\mathrm{r}}}, 0\right]^{2} .
$$

For each breaking wave with phase speed $\mathbf{C}_{\mathrm{b}}$, relative crest velocities of underlying short waves are defined by $\Delta_{\mathbf{C}}=\left|\mathbf{C}-\mathbf{C}_{\mathrm{b}}\right|$. Then, the dissipation rate due to cumulative effect is simply defined by the rate of passage of the long breaking waves over the short underlying waves $\Delta_{\mathbf{C}} \Lambda(\mathbf{C}) \mathrm{d} \mathbf{C}$ where $\Lambda(\mathbf{C}) \mathrm{d} \mathbf{C}$ is the breaking crests length density of wave with phase speed in range $[\mathbf{C}, \mathbf{C}+\mathrm{d} \mathbf{C}]$ introduced by Phillips (1985). $\Lambda(k, \theta) \mathrm{d} k \mathrm{~d} \theta$ is estimated using the length density of crest (breaking or not) $l(k, \theta) \simeq 1 /\left(2 \pi^{2}\right)$ (defined by Ardhuin et al., 2010) with

$$
\Lambda(k, \theta)=P_{\mathrm{b}}(k, \theta) l(k, \theta) .
$$


This yields the cumulative dissipation

$$
S_{\mathrm{bk}, \mathrm{cu}}(k, \theta)=C_{\mathrm{u}} F(k, \theta) \int_{k^{\prime}<r_{\mathrm{cu}}^{2} k} \int_{0}^{2 \pi} \Delta_{\mathbf{C}} \Lambda\left(k^{\prime}, \theta\right) \mathrm{d} \theta \mathrm{d} k^{\prime},
$$

where $r_{\mathrm{cu}}$ defines the maximum ratio between the frequency of the underlying waves wiped out by the breaker and the breaker frequency. This whitecapping dissipation added to the wind-wave generation and swell dissipation is called TEST441b and is fully described by Ardhuin et al. (2010). A minor adjustment of the swell dissipation is described in Appendix A, giving a parameterization TEST451.

As stated in the introduction, Filipot and Ardhuin (2012) filtered the spectrum $E(k)$ with a sliding rectangular windows $R_{f_{i}}$ with finite frequency bandwidth centered in $f_{i}$. Then for each wave scale $f_{i}$, wave steepness is defined from significant wave height $H_{s, f_{i}}$ and mean wavenumber $\bar{k}_{f_{i}}$. The steepness values obtained can be compared to measured wave geometrical properties. Following Thornton and Guza (1983), the Breaking Wave Height Distribution (hereinafter BWHD) is given in each wave scale $f_{i}$ by the product of the Rayleigh distribution of wave heights (breaking or not) $P_{\mathrm{R}, f_{i}}$ times a weight function $W$. Filipot and Ardhuin (2012) used the weight function $W_{\text {FAB }}$ introduced and fully described by Filipot et al. (2010). Then integration of BWHD over wave heights gives the breaking probability of the wave field, so breaking probability of the wave scale $f_{i}$ is then given by

$$
P_{\mathrm{b}, f_{i}}=\int_{0}^{\infty} P_{\mathrm{R}, f_{i}}(H) W_{\mathrm{FAB}, f_{i}}(H) \mathrm{d} H .
$$

The authors also estimated the energy dissipation by unit of breaking crest length $\epsilon(H)$ of breakers with height $H$, adjusting the bore model to all water 
depths (full details in Filipot et al., 2010). Defining $\Pi_{f_{i}}=k_{f_{i}} /(2 \pi)$ as the crest length (breaking or not) of unidirectional waves per square meter in wave scale $f_{i}$, they obtained dissipated energy $Q_{f_{i}}$ with

$$
Q_{f_{i}}=\int_{0}^{\infty} P_{\mathrm{R}, f_{i}}(H) W_{\mathrm{FAB}, f_{i}}(H) \Pi_{f_{i}} \epsilon(H) \mathrm{d} H .
$$

The dissipated energy quantity $Q_{f_{i}}$ is then distributed over the wavenumber contained in the wave scale $f_{i}$ using a weight function of the energy such that

$$
Q_{f_{i}}(k)=Q_{f_{i}} \frac{E(k) \mathrm{d} k}{E_{f_{i}}},
$$

where $E_{f_{i}}$ is the energy in the wave scale $f_{i}$. Due to overlap of the filtering windows, each spectral component participates in several scales. Energy lost by spontaneous breaking $Q_{\mathrm{bk}, \mathrm{sp}}$ is then given by

$$
Q_{\mathrm{bk}, \mathrm{sp}}(k)=\frac{1}{N} \sum_{i=1}^{N} Q_{f_{i}}(k)
$$

where $f_{i \in[1, N]}$ are the wave scales involving $k$.

$Q_{\mathrm{bk}, \mathrm{sp}}(k)$ is then distributed over direction with

$$
Q_{\mathrm{bk}, \mathrm{sp}}(k, \theta)=Q_{\mathrm{bk}, \mathrm{sp}}(k) \frac{E(k, \theta) \mathrm{d} \theta}{E(k)},
$$

Finally, dissipation $S_{\mathrm{bk}, \mathrm{sp}}$ is given by $S_{\mathrm{bk}, \mathrm{sp}}(k, \theta) \mathrm{d} k \mathrm{~d} \theta=Q_{\mathrm{bk}, \mathrm{sp}}(k, \theta)$. Compared to the original algorithm, we now compute $P_{\mathrm{b}, f_{i}}$ by extrapolating the wave spectrum to unresolved high frequencies, assuming a $f^{-5}$ roll-off of the energy spectrum. The bottom panel of figure 1 shows the breaking probabilities obtained with (black line) or without (dashed blue line) this spectral extrapolation.

Because there may be inconsistencies in combining breaking probabilities derived from saturation spectrum (Ardhuin et al., 2010) for cumulative dissipation, and breaking probabilities derived from wave scale analysis (Filipot 
and Ardhuin, 2012) for spontaneous dissipation, we present here a consistent combination.

\subsection{Adaptation of TEST500 into TEST570}

The parameterization TEST500 by Filipot and Ardhuin (2012) is now modified by including both a correction of swell dissipation (Appendix A), and a cumulative effect now consistent with the spontaneous breaking dissipation term. This aspects are implemented in WAVEWATCH III ${ }^{\circledR}$ (hereinafter WWATCH), and we refer to the modified parameterization as TEST570.

From breaking probabilities $P_{\mathrm{b}, f_{i}}$ estimated by equation (7), breaking probabilities $P_{\mathrm{b}}(k)$ at wave wavenumber $k$ is then estimated averaging the $P_{\mathrm{b}, f_{i}}$ of the $N$ wave scales $f_{i \in[1, N]}$ involving $k$,

$$
P_{\mathrm{b}}(k)=\frac{1}{N} \sum_{i=1}^{N} P_{\mathrm{b}, f_{i}} .
$$

The breaking probability is distributed over different directions proportionally to the spectral energy

$$
P_{\mathrm{b}}(k, \theta)=P_{\mathrm{b}}(k) \frac{E(k, \theta)}{\int_{0}^{2 \pi} E(k, \theta) \mathrm{d} \theta} .
$$

Then, $\Lambda(k, \theta)$ is obtained with equation (5) and is now used in equation (6) to provide the cumulative dissipation.

The parameters for spontaneous dissipation are kept equal to those proposed by Filipot and Ardhuin (2012) and parameters for cumulative effect dissipation, $r_{\mathrm{cu}}$ and $C_{\mathrm{u}}$ in equation (6) are kept equal to those proposed by Ardhuin et al. (2010) (see Appendix B). As a result, the only differences with TEST500 are the breaking probabilities used in the cumulative term. 
We note that $C_{\mathrm{u}}=0.6$ is kept whereas it is expected to be close to 1 (Ardhuin et al., 2010). There can be two explanations. First, the crest lengths of all waves, breaking or not, is larger by a factor of two in Ardhuin et al. (2010) compared to Banner and Morison (2010). Using the expression in Banner and Morison (2010), we would arrive at the same model results with $C_{\mathrm{u}}=1.2$. Second, it appears likely that the wind input for the shortest waves is underestimated in the parameterizations described here (Rascle and Ardhuin, A global wave parameter database for geophysical applications. Part 2: model validation with improved source term parameterization, submitted to Ocean Modelling). This low input requires an underestimation of the dissipation rate to produce a correct spectral level. Calibration of the new parameterization leads us to reduce the global swell dissipation factor from 0.70 to 0.65 . The wind input coefficient $\beta_{\max }$ is also decreased from 1.52 to 1.50 (see Appendix B for further details).

A validation of this new parameterization is provided in Appendix C. First, a global validation in terms of wave heights and mean square slopes is shown (Appendix C.1). Then the spectral shape is analysed with a realistic regional hindcast of experiments at sea (Appendix C.2).

From now on, we shall use the parameterizations TEST451, used for operational ocean wave forecasting at NOAA/NCEP since May 2012, and TEST570, now used operationally at NOAA/NCEP for the Great Lakes since 2013, because of their better performance at short fetches. Results with the parameterization of Bidlot et al. (2005) (hereinafter BJA) are given as references, because this parameterization has been used operationally at European Center for Medium-Range Weather Forecasts (hereinafter ECMWF) 
since 2005, with a few minor adjustments (Bidlot, 2012).

\section{Dissipation source terms and breaking crest length densities}

All model results described here use the same spectral grid with 24 directions and 32 frequencies exponentially spaced between 0.037 and $0.7 \mathrm{~Hz}$. In this section, different parameterizations are both used to compute nonlinear interactions between spectral components. Runs named TESTNNN use the Discrete Interaction Approximation (hereinafter DIA) proposed by Hasselmann et al. (1985). Runs noted TESTNNNX use the Webb-Tracy-Resio algorithm for the exact nonlinear interactions (hereinafter XNL), as coded by van Vledder (2006). A diagnostic tail proportional to $f^{-5}$ is imposed at a cut-off frequency $f_{c}=r_{\mathrm{FM}} f_{m}$, with $f_{m}=1 / T_{m 0,1}$. In TEST500X, Filipot and Ardhuin (2012) reduced the value of $r_{\mathrm{FM}}$ to 4.5, to maintain a reasonable energy level in the spectral tail. In the new parameterization TEST570X, as in TEST441bX (Ardhuin et al., 2010), the diagnostic tail is imposed only above $r_{\mathrm{FM}}=9.9$ times the mean frequency, which generally falls outside the model frequency range.

Academic case: Uniform infinite deep ocean

The first model calculations are performed for a single point domain, corresponding to uniform deep ocean conditions. First, the wave evolution is started from rest with a constant wind of $10 \mathrm{~m} \mathrm{~s}^{-1}$. Figure 2 shows breaking probabilities and the associated dissipations obtained after 3 days of simulation, when the wave field is fully developed.

Both parameterizations, TEST570 and TEST451, give similar breaking probability distribution but with a higher level for TEST570. However, the 
abnormal lower breaking probabilities on frequencies just above the peak observed with saturation-based parameterization (TEST451) disappears with wave scale analysis (TEST570), which provides smooth breaking probability distribution over frequencies. As a result, the higher breaking of waves just above the peak leads to a stronger cumulative dissipation $\left(S_{\mathrm{bk}, \mathrm{cu}}\right)$ at high frequencies.

All source terms and spectra are presented in figures 3 (DIA) and 4 (XNL). The net dissipation induced by breaking $S_{\mathrm{oc}}=S_{\mathrm{bk}, \mathrm{sp}}+S_{\mathrm{bk}, \mathrm{cu}}$ is shifted to lower frequencies in the new parameterization TEST570 compared to the result given by TEST451.

With the more accurate estimation of the non-linear source term $S_{\mathrm{nl}}$, the spectral level is artificially higher in the highest two spectral bins. This artefact is due to a kink in the spectrum between the resolved spectral range and the assumed tail shape beyond the highest resolved frequency. However, the breaking probability distribution is not much affected, as shown on figure 5 .

We now compare the two parameterizations in terms of breaking crest length distribution $\Lambda(\mathbf{C})$ defined by equation 5 . Here we use the linear dispersion relation to estimate the crest velocities $C$ from the wavenumbers $k$.

Model calculations are performed for the single point (uniform ocean) started from rest, described above with uniform winds $\left(U_{10}=5,10\right.$, and $15 \mathrm{~m} . \mathrm{s}^{-1}$ ), during 48 hours (Fig. 5). We note that observations show a maximum of the $\Lambda$-distribution (Gemmrich et al., 2008; Thomson and Jessup, 2008), which is not reproduced by either parameterization. This could be 
partially explained by the absence of bubble generation in the breaking of short waves $(C<1.5-2 \mathrm{~m} / \mathrm{s})$. However, infrared observations show that such a maximum also occurs for short gravity waves (Jessup and Phadnis, 2005). In TEST451, the increase in directional spreading towards high frequencies tends to reduce the direction-dependent saturation, but this reduction is not sufficiently pronounced to make $\Lambda(\mathbf{C})$ decrease for small values of $C$. We have tried a similar generalization of TEST570 in which the spectrum would only be integrated over an angular sector to give the wave steepness from which breaking probabilities are derived. In this case $\Lambda(\mathbf{C})$ can also be reduced but it would also take a very steep spectral decay, close to $f^{-6}$ to produce a maximum in $\Lambda(\mathbf{C})$. Such a spectral variation is not supported by observations (e.g. Banner et al., 1989; Kosnik and Dulov, 2011).

The smooth shape of $\Lambda(C)$ around the peak given by TEST570 is in accordance with the $C^{-6}$ asymptote proposed by Phillips (1985) from the generation and dissipation balance, and observed in experiments by Gemmrich et al. (2008), Melville and Matusov (2002), Mironov (2009), and Kleiss and Melville (2011). However, the level of this asymptote is lower by a factor $\approx 4$ than in the observations of Gemmrich et al. (2008) and could be again reduced by a factor of 2 using the expression of the crest lengths of all waves, breaking or not, given by Banner and Morison (2010). In contrast, $\Lambda$ distributions given by TEST451, with a clear minimum for phase speeds just below those of dominant waves, are not consistent with the observed distributions.

The top panels in figure 6 show the evolution of the wave spectrum (left) and the associated $\Lambda$-distribution (right). The bottom panel shows the evo- 
lution of the $\Lambda$-distribution value at the frequency peak $\left(\Lambda_{p}\right)$ for the various parameterizations. We have used $U_{10}=12 \mathrm{~m} \mathrm{~s}^{-1}$, allowing a direct comparison with the model results of (Banner and Morison, 2010, their figure 8b). Both parameterizations tested here provide values of $\Lambda_{p}$ in good agreement with this other model. Nevertheless, we remark that using the DIA or XNL methods for the nonlinear interactions slightly modifies values of $\Lambda_{p}$, with higher levels obtained when using XNL, compared to results obtained with the DIA parameterization.

\section{Waves and whitecaps at the global scale}

In this section, we consider the global hindcast of the year 2006, for which we obtained the WindSat radiometer data interpreted by Anguelova and Webster (2006). The model uses a 0.5-degree regular resolution in longitude and latitude. ECMWF operational analyses for the wind and sea ice concentration are used as forcing fields, with the addition of sub-grid blocking of waves by small icebergs in the Southern Ocean, using the method and iceberg dataset described by Ardhuin et al. (2011b). The non-linear source term is now computed using only the DIA (Hasselmann et al., 1985). This same model is validated in terms of wave height and mean square slope in Appendix C.1. The low error levels for both parameters, typically $10 \%$ of the observed RMS values, indicates a generally good representation of the frequency spectrum. We now consider our estimations of whitecap coverage in relation to the radiometer data of Anguelova et al. (2009).

In order to be consistent with radiometer data, we define the whitecap coverage (WCC) as the fraction of sea surface covered by both active breaking 
(stage A) and residual foam (stage B). Although stage A is more closely related to breaking fronts, which is what we model, these two stages are difficult to separate in microwave radiometric data. This combination with stage B introduces a large variability due to other factors, such as water temperature and salinity, which we have not introduced in our model.

For a single breaker, the area covered by foam is obtained by multiplying the breaking crest length by a mean whitecap width parameterized as the constant fraction $\kappa=\kappa_{\mathrm{A}}+\kappa_{\mathrm{B}}$ of breaker wavelength $\lambda$. Mironov (2009) has found that the geometry of phase A is well represented by ellipses of almost constant eccentricity with breaking crest lengths distributed as a power-law. These observations are consistent with the use of a constant $\kappa_{\mathrm{A}}$. Reul and Chapron (2003) also proposed a $\kappa_{\mathrm{A}}$ constant to represent stage A. Based on laboratory observations of Duncan (1981), they used $\kappa_{\mathrm{A}}=0.3$. Our parameterization for both stages $\mathrm{A}$ and $\mathrm{B}$ is based on the fact that, for constant environmental parameters, stage B is related to stage A.

The whitecap coverage, corresponding to the fraction of sea surface covered by both stages, is here estimated as

$$
W=\int_{0}^{\infty} \kappa \lambda_{C} \Lambda(C) \mathrm{d} C
$$

where $\lambda_{C}$ is the wavelength of breaking waves with phase speed $C$. In deep water, the wavelength is proportional to the squared phase speed $\left(\lambda_{C}=\right.$ $\left.2 \pi C^{2} / g\right)$. Therefore, whitecap coverage from breaking wave with velocities in range $C$ to $C+\mathrm{d} C$ in deep water is proportional to the second moment of $\lambda_{C}$ (Reul and Chapron, 2003) and the total whitecap coverage, in deep 
water, is given by

$$
W=\int_{0}^{\infty} \kappa 2 \pi \cdot \frac{C^{2}}{g} \Lambda(C) \mathrm{d} C .
$$

We have adjusted the constant $\kappa$ for each parameterization, to provide whitecap coverage consistent with empirical wind-driven fit by Monahan and Woolf (1989) and the global whitecap coverage database of Anguelova et al. (2009). $\kappa$ is adjusted to 0.30 for TEST451 and 0.18 for TEST570.

The figure 7 shows $W$ binned as a function of $U_{10}$ for both model parameterizations using ECMWF forcing wind and satellite observations of whitecap coverage by Anguelova et al. (2009) for the month of March 2006. The blue line corresponds to the empirical wind-dependent expression by Monahan and Woolf (1989), based on video data analysis. The whitecap coverages were derived from WindSat observations by Anguelova et al. (2009), using the methodology of Anguelova and Webster (2006). They used $10 \mathrm{GHz}$ and $37 \mathrm{GHz}$ radiometric measurements in horizontal polarization across the WindSat swath, giving respectively $W_{10 H}$ and $W_{37 H}$. The model and observed $W$ are then interpolated on the satellite measurements, and then averaged over 1 degree in latitude along the satellite track. The general dependence of $W$ on the wind speed is relatively well reproduced with a good correlation between modeled whitecap coverage and formula by Monahan and Woolf (1989), mainly for $U_{10}<15 \mathrm{~m} / \mathrm{s}$. For higher winds $\left(U_{10}>15 \mathrm{~m} / \mathrm{s}\right)$, both parameterizations provide a linear dependence of WCC to wind speed, which is consistent with satellite observations. We remember here that the absolute level of $W$ is controlled by $\kappa$. Using model wind field, independent of wind observation, by Anguelova et al. (2009), differences between observed wind under satellite track and collocated ECMWF winds leads to a large 
spread of $W_{\text {obs }}$ for a given wind speed. However, this spread shrinks when satellite winds are used, because the wind speed is then estimated from the same brightness temperature used to derive the WCC. Direct comparison between values of modeled and observed WCC on collocated points is shown in figure 8. Modeled whitecap coverages are slightly better correlated than an empirical estimate using Monahan and Woolf (1989) and model wind speeds $\left(R^{2}=0.53\right.$ instead of 0.5$)$, but this improvement is very far from the impact reported by Hanson and Phillips (1999) who used measured wind trends in addition to measured wind speeds. Although geophysical and measurement factors contribute to the scatter, we expect that both the wave modelling and the modelled ECMWF winds are responsible for the larger errors in our model results.

We finally attempted to estimate the mean vertical foam thickness. For this purpose, we modeled the average vertical thickness of foam-layers following Reul and Chapron (2003) (Fig.3, Eq.5), who considered stage A and B of breaking separately. During active breaking (stage A), vertical thickness grows linearly (equation 16 ) to reach a maximum value $\overline{\delta_{\max }}=0.4 \tau^{*} / k$. Then, foam thickness decreases exponentially with a time constant $\tau^{\prime}$ (stage B) (equation 17). Following Reul and Chapron (2003), the persistence time of active breaking is set to $\tau^{*}=0.8 T$ and global persistence of a foam-layer, including stage $\mathrm{A}$ and $\mathrm{B}$ is set to $\tau_{\max }=5 T$ with $T$ the period of the breaking wave. $\tau_{\max }$ represents the duration between the beginning of the breaking event and the time at which the foam thickness is practically zero. Time evolution of foam thickness $\bar{\delta}(C, t)$ for a wave with phase speed $C$ is estimated 
for $0<t<\tau^{*}$ using:

$$
\bar{\delta}(C, t)=\frac{\overline{\delta_{\max }}(C)}{\tau^{*}} t
$$

and for $\tau^{*}<t<\tau_{\max }$ using

$$
\bar{\delta}(C, t)=\overline{\delta_{\max }}(C) \exp \left(-\frac{t-\tau^{*}}{\tau^{\prime}}\right)
$$

where the relaxation time $\tau^{\prime}$ is equal to $3.8 \mathrm{~s}$ (salt water). Time evolution of vertical thickness is integrated over the foam time persistence to obtain mean foam thickness $\bar{\Delta}(C)$ of individual breaking events:

$$
\bar{\Delta}(C)=\frac{\overline{\delta_{\max }}(C)}{\tau_{\max }}\left(\frac{1}{2}+3.8\left(1-\exp \left(-\frac{\tau_{\max }-\tau^{*}}{3.8}\right)\right)\right)
$$

Integration of the whitecap coverage produced by each scale times its mean foam thickness over all wave scales gives a global mean foam thickness

$$
\bar{\Delta}=\int_{0}^{\infty} \bar{\Delta}(C) \kappa \lambda(C) \Lambda(C) \mathrm{d} C
$$

Figure 9 shows the dependence between the mean foam thickness and the wind speed for the two parameterizations. Higher breaking probabilities just above the peak in TEST570 than ones in TEST451 lead to a sightly higher level of mean foam thickness. This difference increases with wind speed due to displacement of the peak to longer waves which produce higher foam layers. More importantly, for a fixed wind speed, the relative variability of foam thickness is much larger than the variability observed in whitecap coverage values. This suggests that radiometric data at larger wavelengths, which are more sensitive to foam thickness, may be a good indicator of breaking activity beyond the usual wind-whitecap coverage relation of which the Beaufort scale for wind speeds is a perfect example. 


\section{Conclusion and Perspectives}

The TEST570 parameterization presented here accounts for the physical relationship that intrinsically links spontaneous breaking dissipation and dissipation induced by breaking waves (cumulative term) and thereby extends the work of Filipot and Ardhuin (2012). The cumulative dissipation term was adjusted so that the model could reproduce observed spectral evolution and global wave heights distributions. It is found that this TEST570 parameterization produces breaking crest lengths distributions that are in better qualitative agreement with observations, contrary to TEST451 which fails to produce smooth $\Lambda$-distributions. This difference is clearly associated with the integration over frequencies in TEST570 compared to the local saturation used in TEST451. Banner and Morison (2010) have shown that estimating breaking parameters after smoothing the local saturations over frequencies has the same effect.

Overall, as already shown by Banner and Morison (2010), an explicit modeling of whitecap properties provides a new constraint on the model dissipation source terms, and a more detailed use of global observations from satellite radiometers, such as interpreted by Anguelova and Webster (2006), can be used for this. In particular, we find that joint estimates of the whitecap coverage and foam thickness could be an interesting way to discriminate between different sea states or parameterizations. This can be achieved by combining radiometric measurements from different bands. Recent results by Reul et al. (2006) with $L$-band radiometric measurements in Hurricanes using the Soil Moisture and Ocean Salinity space mission can be combined with the $\mathrm{Ku}$ and $\mathrm{X}$ band data to provide the necessary information. 
Further work on the parameterization remains, in particular on the method to attribute breaking probabilities and dissipation rates to different directions, and in the physical processes represented in the cumulative term. Indeed, the cumulative effect parameterization of Ardhuin et al. (2010) used with isotropic breaking probability tends to reduce the width of the directional spectrum. All the parameterizations tested here produce directional spectra which are too narrow at high frequencies $(f>0.6 \mathrm{~Hz}$ in typical oceanic conditions). We attribute this deficiency to a lack of physical processes in the model. In particular the splash of breakers has been shown to transfer energy to high frequencies by creating small waves (Rozenberg and Ritter, 2005, e.g.), and short waves are known to break mostly at the crest of longer waves, due to hydrodynamic and aerodynamic modulations (e.g. Smith, 1986).

\section{Appendix A. Correction of swell dissipation}

The essence of that modification is a smoothing of the swell dissipation function around the threshold for transition between laminar and turbulent conditions. This was done by introducing a weighted average of the laminar $S_{\text {out,l }}(f, \theta)$ and turbulent $S_{\text {out,t }}(f, \theta)$ dissipation source terms respectly given by equations (8) and (9) of Ardhuin et al. (2010),

$$
S_{\text {out }}(f, \theta)=(0.5+\alpha) S_{\text {out }, 1}(f, \theta)+(0.5-\alpha) S_{\text {out }, \mathrm{t}}(f, \theta)
$$

where the smoothing parameter is defined by,

$$
\alpha=0.5 \tanh \left[\left(\pi H_{s}^{3} /\left(4 \nu T_{\mathrm{m} 0,2}\right)-s_{4}\right) / s_{7}\right],
$$


where $\nu=1.4 \times 10^{-5} \mathrm{~m}^{2} \mathrm{~s}^{-1}$ is the air viscosity, $T_{\mathrm{m} 0,2}$ is the mean wave period and $s_{4}=10^{5} \mathrm{~m}$ and $s_{7}=2.3 \times 10^{5} \mathrm{~m}$ are fitting parameters.

The new parameterization reduced the global errors on wave height by $4 \%$ on average (Fig. A.10). More importantly it corrected the abnormal distribution of significant wave heights.

\section{Appendix B. Model settings for the different parameterizations}

Table B.1 gives the values of the different namelist parameters to reproduce the present results. They can be used in version 4.04 to 4.08 of WWATCH.

\section{Appendix C. Validation of the updated (TEST570) parameteriza- tion}

Appendix C.1. Global validation for all of 2006

Although not central to the present paper, the model performance in terms of significant wave height $H_{s}$ and mean square slope (mss) is important for other applications. Our validation uses altimeter data from ERS2, ENVISAT, Jason-1 and GFO-Sat, assembled in the Globwave database (Queffeulou and Croizé-Fillon, 2010). The model results from three-hourly gridded output are interpolated on the satellite track position every second. Both model and data are then averaged over 1 degree in latitude along the track. These averaged parameters are then binned geographically or according the wind speed and wave height.

Figure C.11 shows the similar biases and random errors of the TEST570 and TEST451 parameterizations. These are also close to the results of 
TEST500 (not shown, see Filipot and Ardhuin 2012). These results contrast with the very different error pattern obtained with the BJA parameterization by Bidlot et al. (2005), which is shown for reference. BJA produces larger normalized errors, with large biases for low wave heights, due to an underestimation of swell dissipation, in particular in the Pacific Ocean. That effect is generally well corrected in the operational ECMWF by the assimilation of altimeter data. Other aspects of these differences are discussed by Ardhuin et al. (2010). TEST570 generally yields slightly larger random errors compared to TEST451 but, similar to TEST500 (Filipot and Ardhuin, 2012), it also has less bias for the significant wave height in enclosed seas such as the Gulf of Mexico, the Mediterranean Sea or Hudson Bay, giving smaller overall errors there.

When the data is binned according to wave height, as shown on figure C.12, we see that the swell dissipation correction of TEST451 has removed most of the strange biases in TEST441b for heights between 1 and $3 \mathrm{~m}$ (Ardhuin et al., 2011a, Fig. 1). Because they share the same swell treatment, the same benefits are found in TEST570 compared to TEST500. For larger wave heights, the negative bias with TEST451 is greatly reduced in TEST570. However, this reduced bias for the highest wave ranges should be considered with caution, given the general underestimation of high winds in the ECMWF analyses (Ardhuin et al., 2011a; Hanafin et al., 2012). It is likely that, for these phenomenal seas, an overestimation of the wave growth is compensating for a low bias in the ECMWF wind speeds. Results are also given using CFSR wind as forcing wind fields. In this case, wind input coefficients are reduced to $\beta_{\max , \mathrm{CFSR}}=1.33$ (Ardhuin et al., 2011a) for TEST451 and we consistently 
fix $\beta_{\max , \mathrm{CFSR}}$ to 1.30 for TEST570.

A complementary and interesting diagnostic of the model performance is provided by the altimeter normalized radar cross sections (NRCS) that can be interpreted as the mean square slope of the sea surface (Barrick, 1968; Vandemark et al., 2004). Although the absolute calibrations of the NRCS and thus the mean square slope estimation are difficult, their relative variations with wave height, for a fixed wind speed, should follow the variations of the true mean square slope. Ardhuin et al. (2010) showed that, in wave model estimates, this variation is strongly modified by the cumulative parameterization and the sheltering effect in the wind-wave generation term.

The TEST451 parameterization inherits the tuning performed for TEST441b and generally gives a realistic spread in mean square slope for a fixed wind speed, in particular for low wind speeds (Fig. C.13). Using same cumulative term, TEST500 (not shown here) gives a similar spread. In contrast the distribution $\operatorname{mss}_{\mathrm{ku}}\left(U_{10}, H_{s}\right)$ shown for TEST570 is narrower than the observed distribution and biases to relatively high values. This behavior suggests that the cumulative effect may be overestimated in TEST570, i.e. the short waves that contribute strongly to the mean square slope are not energetic enough. This could be caused by an overestimation of the breaking probabilities at the largest wave scales. The other possibility is that the sheltering effect is exaggerated, giving a too strong reduction of wave generation at high frequencies. That latter hypothesis is consistent with the nearly inexistent variability of wave-supported stress with wave age in both TEST451 and TEST570. 
Appendix C.2. Fetch-limited case: SHOWEX hindcast

Due to its important effect on the spectral shape, wave breaking dissipation also influences the wind input source term, which controls the wave field growth. This wave growth and associated spectral shape, is evaluated with a hindcast of a fetch-limited case measured during SHOWEX, on November 3, 1999 (Ardhuin et al., 2007). The $1 \mathrm{~m}$ high swell present with a peak frequency of $0.1 \mathrm{~Hz}$ during the experiment is included in the model offshore boundary from the X6 buoy measurements. Details on buoy location and observed data analysis are given by Ardhuin et al. (2007). The model configuration uses the same model grid as the one used in Ardhuin et al. (2010) with a resolution of $0.016 \mathrm{deg}(\approx 1.6 \mathrm{~km})$. Wind forcing is taken from the Climate Forecast System Reanalysis (Saha et al., 2010).

The wind blows offshore with a direction 20 degrees from shore-normal, which results in a particular slanting fetch wind sea for buoys such as X2, located $25 \mathrm{~km}$ from shore. Ardhuin et al. (2007) showed how the strength of the input and dissipation source term influence the mean direction in these slanting fetch conditions. Wave directions align with the wind for strong forcing, and wave directions align in the longest fetch (alongshore) for the longer and more weakly forced components. As they also strongly control the spectral shape, non-linear interactions also influence the wave field growth, as reported by Gagnaire-Renou et al. (2010). Here, both DIA and XNL methods are used to estimate the non-linear source term.

Overall, we find a good agreement between model and measurements in terms of energy and mean directions (Fig. C.14, top and middle panels). The shift in mean direction at the location of buoy X2, from the wind direc- 
tion at high frequency to the alongshore direction at low frequency, occurs at a slightly lower frequency in TEST570 compared to TEST451, due to a faster development of the wind sea with the new parameterization. Modeled directional spreads are more problematic (Fig. C.14, bottom panels). They are underestimated for all parameterizations, especially for TEST570, due to a stronger cumulative effect, because short waves in oblique directions are more easily taken over by the large breakers in the main direction. That narrowing effect is partly compensated in TEST451 by the broadening associated with the stronger spontaneous breaking in the mean direction, but in the case of an isotropic dissipation term such as used in TEST570 or by van der Westhuysen et al. (2007), the produced spectra are too narrow.

\section{Acknowledgments}

We warmly thank Johannes Gemmrich, Mickael Banner and Russel Morison for providing breaking wave and wave spectra data from the FAIRS experiment. We also thank Magdalena Anguelova and Ferris Webster for sharing their global whitecap database. Finnaly, the helpful remarks of several anonymous reviewers are gratefully acknowleded.

This work is supported by a FP7-ERC young investigator grant number 240009 for the IOWAGA project, the U.S. National Ocean Partnership Program, under grant U.S. Office of Naval Research grant N00014-10-1-0383. Additional support from ESA and CNES for the Globwave project is gratefully acknowledged.

Alves, J.H.G.M., Banner, M.L., 2003. Performance of a saturation-based 
dissipation-rate source term in modeling the fetch-limited evolution of wind waves. J. Phys. Oceanogr. 33, 1274-1298.

Anguelova, M.D., Bobak, J.P., Asher, W.E., Dowgiallo, D.J., Moat, B.I., Pascal, R.W., Yelland, M.J., 2009. Validation of satellite-based estimates of whitecap coverage: Approaches and initial results, in: 16th Air-Sea Interaction conference, AMS, Phoenix, Arizona.

Anguelova, M.D., Webster, F.W., 2006. Whitecap coverage from satellite measurements: a first step toward modeling the variability of oceanic whitecaps. J. Geophys. Res. 111, C03017.

Ardhuin, F., Chapron, B., Collard, F., 2009. Observation of swell dissipation across oceans. Geophys. Res. Lett. 36, L06607.

Ardhuin, F., Hanafin, J., Quilfen, Y., Chapron, B., Queffeulou, P., Obrebski, M., Sienkiewicz, J., Vandemark, D., 2011a. calibration of the IOWAGA global wave hindcast (1991-2011)

using ECMWF and CFSR winds, in: Proceedings, 12th Int. Workshop of Wave Hindcasting and Forecasting, Hawaii.

Ardhuin, F., Herbers, T.H.C., Watts, K.P., van Vledder, G.P., Jensen, R., Graber, H., 2007. Swell and slanting fetch effects on wind wave growth. J. Phys. Oceanogr. 37, 908-931.

Ardhuin, F., Jenkins, A.D., 2006. On the interaction of surface waves and upper ocean turbulence. J. Phys. Oceanogr. 36, 551-557.

Ardhuin, F., Rogers, E., Babanin, A., Filipot, J.F., Magne, R., Roland, A., van der Westhuysen, A., Queffeulou, P., Lefevre, J.M., Aouf, L., Collard, 
F., 2010. Semi-empirical dissipation source functions for wind-wave models: part I, definition, calibration and validation. J. Phys. Oceanogr. 40, 1917-1941.

Ardhuin, F., Roland, A., 2012. Coastal wave reflection, directional spreading, and seismo-acoustic noise sources. J. Geophys. Res. 117, in press.

Ardhuin, F., Stutzmann, E., Schimmel, M., Mangeney, A., 2011b. Ocean wave sources of seismic noise. J. Geophys. Res. 116, C09004.

Babanin, A.V., Tsagareli, K.N., Young, I.R., Walker, D.J., 2010. Numerical investigation of spectral evolution of wind waves. part II: Dissipation term and evolution tests. J. Phys. Oceanogr. 40, 667-683.

Banner, M.L., Babanin, A.V., Young, I.R., 2000. Breaking probability for dominant waves on the sea surface. J. Phys. Oceanogr. 30, 3145-3160.

Banner, M.L., Gemmrich, J.R., Farmer, D.M., 2002. Multiscale measurement of ocean wave breaking probability. J. Phys. Oceanogr. 32, 3364-3374.

Banner, M.L., Jones, I.S.F., Trinder, J.C., 1989. Wavenumber spectra of short gravity waves. J. Fluid Mech. 198, 321-344.

Banner, M.L., Morison, R.P., 2010. Refined source terms in wind wave models with explicit wave breaking prediction. part I: Model framework and validation against field data. Ocean Modelling 33, 177-189.

Banner, M.L., Tian, X., 1998. On the determination of the onset of breaking for modulating surface gravity water waves. J. Fluid Mech. 367, 107-137. 
Barrick, D.E., 1968. Rough surface scattering based on the specular point theory. IEEE Trans. Antennas Propagat. AP-14, 449-454.

Bidlot, J., Abdalla, S., Janssen, P., 2005. A revised formulation for ocean wave dissipation in CY25R1. Technical Report Memorandum R60.9/JB/0516. Research Department, ECMWF, Reading, U. K.

Bidlot, J.R., 2012. Present status of wave forecasting at e.c.m.w.f., in: Workshop on Ocean Waves, ECMWF.

Chawla, A., Kirby, J.T., 2002. Monochromatic and random wave breaking at blocking points. J. Geophys. Res. 107, 3067.

Droppleman, J.D., 1970. Apparent microwave emissivity of sea foam. J. Geophys. Res. 75(3), 696-698.

Duncan, J.H., 1981. An experimental investigation of breaking waves produced by a towed hydrofoil. Proc. Roy. Soc. Lond. A 377, 331-348.

Filipot, J.F., Ardhuin, F., 2012. A unified spectral parameterization for wave breaking: from the deep ocean to the surf zone. J. Geophys. Res. 116.

Filipot, J.F., Ardhuin, F., Babanin, A., 2010. A unified deep-to-shallowwater wave-breaking probability parameterization. J. Geophys. Res. 115, C04022.

Gagnaire-Renou, E., Benoit, M., Forget, P., 2010. Ocean wave spectrum properties as derived from quasi-exact computations of nonlinear wavewave interactions. J. Geophys. Res. 115, C12058. 
Gelci, R., Cazalé, H., Vassal, J., 1957. Prévision de la houle. La méthode des densités spectroangulaires. Bulletin d'information du Comité d'Océanographie et d'Etude des Côtes 9, 416-435.

Gemmrich, J.R., Banner, M.L., Garrett, C., 2008. Spectrally resolved energy dissipation rate and momentum flux of breaking waves. J. Phys. Oceanogr. 38, 1296-1312.

Hanafin, J., Quilfen, Y., Ardhuin, F., Vandemark, D., Chapron, B., Feng, H., Sienkiewicz, J., Queffeulou, P., Obrebski, M., Chapron, B., Reul, N., Collard, F., Cormand, D., de Azevedo, E.B., Vandemark, D., Stutzmann, E., 2012. Phenomenal sea states and swell radiation: a comprehensive analysis of the 12-16 February 2011 North Atlantic storms. Bull. Amer. Meterol. Soc. In press.

Hanson, J.L., Phillips, O.M., 1999. Wind sea growth and dissipation in the open ocean. J. Phys. Oceanogr. 29, 1633-1648.

Hasselmann, S., Hasselmann, K., Allender, J., Barnett, T., 1985. Computation and parameterizations of the nonlinear energy transfer in a gravitywave spectrum. Part II: Parameterizations of the nonlinear energy transfer for application in wave models. J. Phys. Oceanogr. 15, 1378-1391.

Holthuijsen, L.H., Powell, M.D., Pietrzak, J.D., 2012. Wind and waves in extreme hurricanes. J. Geophys. Res. 117, C09003.

Jessup, A.T., Phadnis, K.R., 2005. Measurement of the geometric and kinematic properties of microscale breaking waves from infrared imagery using a PIV algorithm. Meas. Sci. Technol. 16, 1961-1969. 
Kantha, L., Wittmann, P., Sclavo, M., Carniel, S., 2009. A preliminary estimate of the stokes dissipation of wave energy in the global ocean. Geophys. Res. Lett. 36, L02605.

Kleiss, J.M., Melville, W.K., 2011. The analysis of sea surface imagery for whitecap kinematics. J. Atmos. Ocean Technol. 28, 219-243.

Komen, G.J., Hasselmann, K., Hasselmann, S., 1984. On the existence of a fully developed windsea spectrum. J. Phys. Oceanogr. 14, 1271-1285.

Kosnik, M.V., Dulov, V.A., 2011. Extraction of short wind wave spectra from stereo images of the sea surface. Measurement Science and Technology 22, 015504.

Melville, W.K., Matusov, P., 2002. Distribution of breaking waves at the ocean surface. Nature 417, 58-63.

Melville, W.K., Verron, F., White, C.J., 2002. The velocity field under breaking waves: coherent structures and turbulence. J. Fluid Mech. 454, 203-233.

Mironov, A.S., 2009. Experimental investigation of statistical and kinematical properties of breaking wind waves. Ph.D. thesis. Marine Hydrophysics Institue, Sebastopol. In Russian.

Mironov, A.S., Dulov, V.A., 2008. Detection of wave breaking using sea surface video records. Meas. Sci. Technol. 19, 015405.

Monahan, E.C., Muircheart, I.Ó., 1981. Optimal power-law description of 
oceanic whitecap coverage dependence on wind speed. J. Phys. Oceanogr. 10, 2094-2099.

Monahan, E.C., Woolf, D.K., 1989. Comments on "variations of whitecap coverage with wind stress and water temperature". J. Phys. Oceanogr. 19, 706-709.

Phillips, O.M., 1984. On the response of short ocean wave components at a fixed wavenumber to ocean current variations. J. Phys. Oceanogr. 14, $1425-1433$.

Phillips, O.M., 1985. Spectral and statistical properties of the equilibrium range in wind-generated gravity waves. J. Fluid Mech. 156, 505-531.

Queffeulou, P., Croizé-Fillon, D., 2010. Global altimeter SWH data set, Version 7, May 2010. Technical Report. Ifremer. URL:http://tinyurl.com/2cj5sez.

Rascle, N., Ardhuin, F., Queffeulou, P., Croizé-Fillon, D., 2008. A global wave parameter database for geophysical applications. part 1: wave-current-turbulence interaction parameters for the open ocean based on traditional parameterizations. Ocean Modelling 25, 154-171. Doi:10.1016/j.ocemod.2008.07.006.

Reul, N., Chapron, B., 2003. A model of sea-foam thickness distribution for passive microwave remote sensing applications. J. Geophys. Res. 108, 3321. Doi:10.1029/2003JC001887.

Reul, N., Tenerelli, J., Chapron, B., Vandemark, D., Quilfen, Y., Kerr, Y., 
2006. Smos satellite l-band radiometer: A new capability for ocean surface remote sensing in hurricanes. J. Geophys. Res. 117, C02006.

Rogers, W.E., Babanin, A.V., Wang, D.W., 2012. Observation-consistent input and whitecapping dissipation in a model for wind-generated surface waves: Description and simple calculations. J. Atmos. Ocean Technol. 29, $1329-1346$.

Rozenberg, A., Ritter, M., 2005. Laboratory study of the fine structure of short surface waves due to breaking: Two-directional wave propagation. J. Geophys. Res. 110, C02011.

Saha, S., Moorthi, S., Pan, H.L., Wu, X., Wang, J., Nadiga, S., Tripp, P., Kistler, R., Woollen, J., Behringer, D., Liu, H., Stokes, D., Grumbine, R., Gayno, G., Wang, J., Hou, Y.T., ya Chuang, H., Juang, H.M.H.a.J.S., Iredell, M., Treadon, R., Kleist, D., Delst, P.V., Keyser, D., Derber, J., Ek, M., Meng, J., Wei, H., Yang, R., Lord, S., van den Dool, H., Kumar, A., Wang, W., Long, C., Chelliah, M., Xue, Y., Huang, B., Schemm, J.K., Ebisuzaki, W., Lin, R., Xie, P., Chen, M., Zhou, S., Higgins, W., Zou, C.Z., Liu, Q., Chen, Y., Han, Y., Cucurull, L., Reynolds, R.W., Rutledge, G., Goldberg, M., 2010. The NCEP Climate Forecast System Reanalysis. Bull. Amer. Meterol. Soc. 91, 1015-1057.

Smith, J., 1986. Short surface waves with growth and dissipation. J. Geophys. Res. 91, 2616-2632.

Thomson, J., Jessup, A.T., 2008. A fourier-based method for the distribution 
of breaking crests from video observations. J. Atmos. Ocean Technol. 26, 1663-1671.

Thornton, E.B., Guza, R.T., 1983. Transformation of wave height distribution. J. Geophys. Res. 88, 5,925-5,938.

Vandemark, D., Chapron, B., Sun, J., Crescenti, G.H., Graber, H.C., 2004. Ocean wave slope observations using radar backscatter and laser altimeters. J. Phys. Oceanogr. 34, 2825-2842.

van Vledder, G.P., 2006. The WRT method for the computation of non-linear four-wave interactions in discrete spectral wave models. Coastal Eng. 53, $223-242$.

van der Westhuysen, A.J., Zijlema, M., Battjes, J.A., 2007. Saturation-based whitecapping dissipation in SWAN for deep and shallow water. Coastal Eng. 54, 151-170.

WISE Group, 2007. Wave modelling - the state of the art. Progress in Oceanography 75, 603-674.

Young, I.R., Babanin, A.V., 2006. Spectral distribution of energy dissipation of wind-generated waves due to dominant wave breaking. J. Phys. Oceanogr. 36, 376-394. 


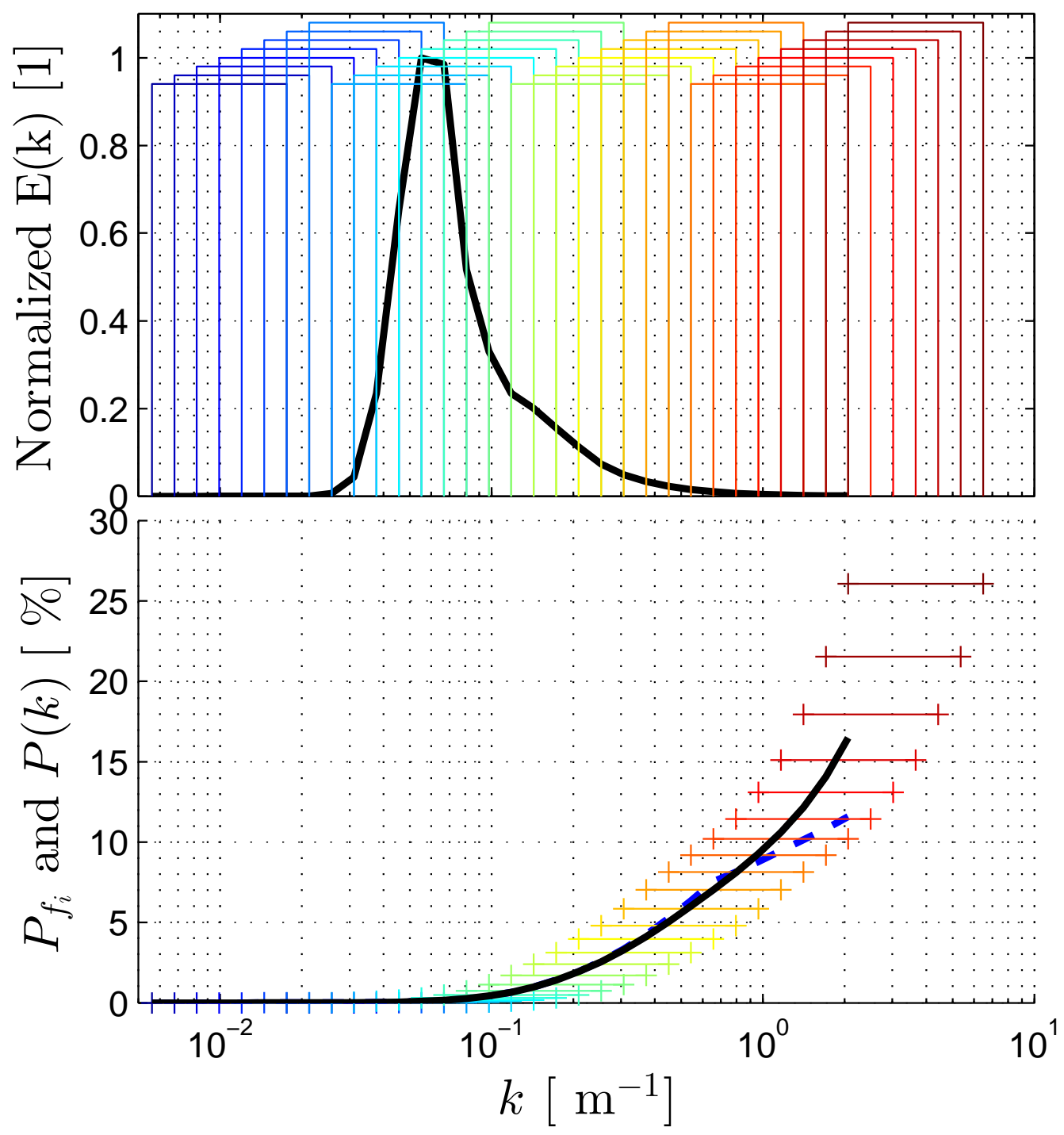

Figure 1: Top: Rectangular filtering windows $W_{f_{i}}$ (colours) over integrated spectrum (black line). Bottom: Breaking probabilities $P_{\mathrm{b}, f_{i}}$ obtained for each wave scale $f_{i}$ (colours) and breaking probability $P_{\mathrm{b}}(k)$ obtained with averaging (Black line). The blue line is the breaking probability $P_{\mathrm{b}}(k)$ without spectrum extrapolation. 

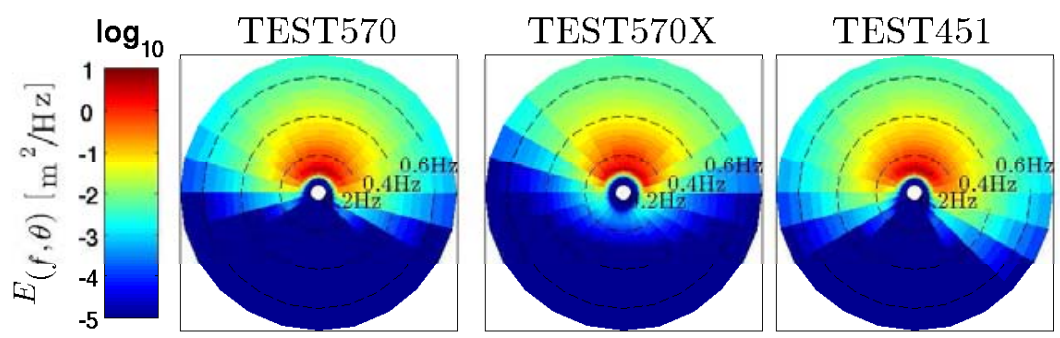

TEST451X
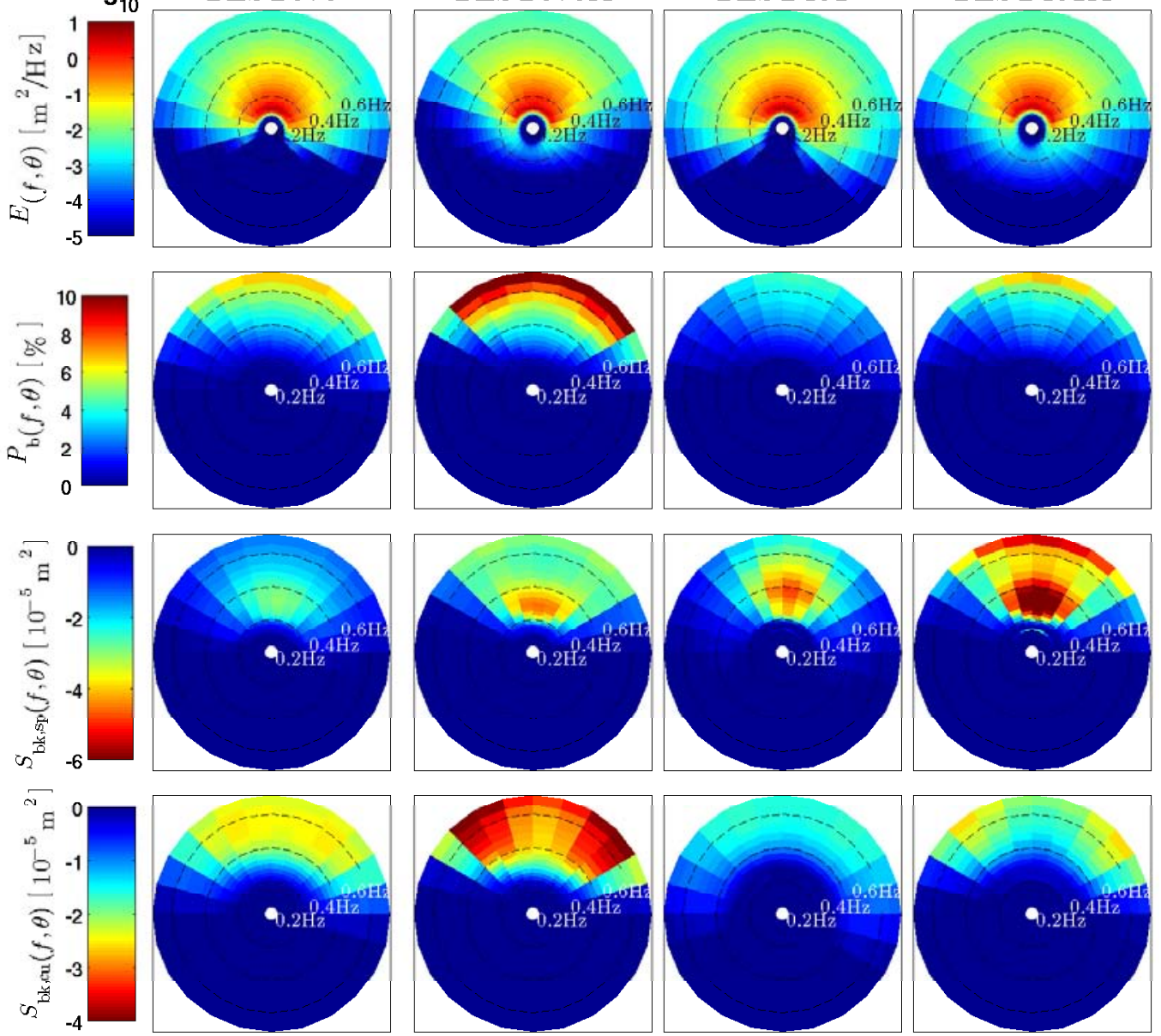

Figure 2: Breaking probabilities and associated dissipations obtained for a fully developed sea state (3 days of simulation) for TEST570 (left) and TEST451 (right) 

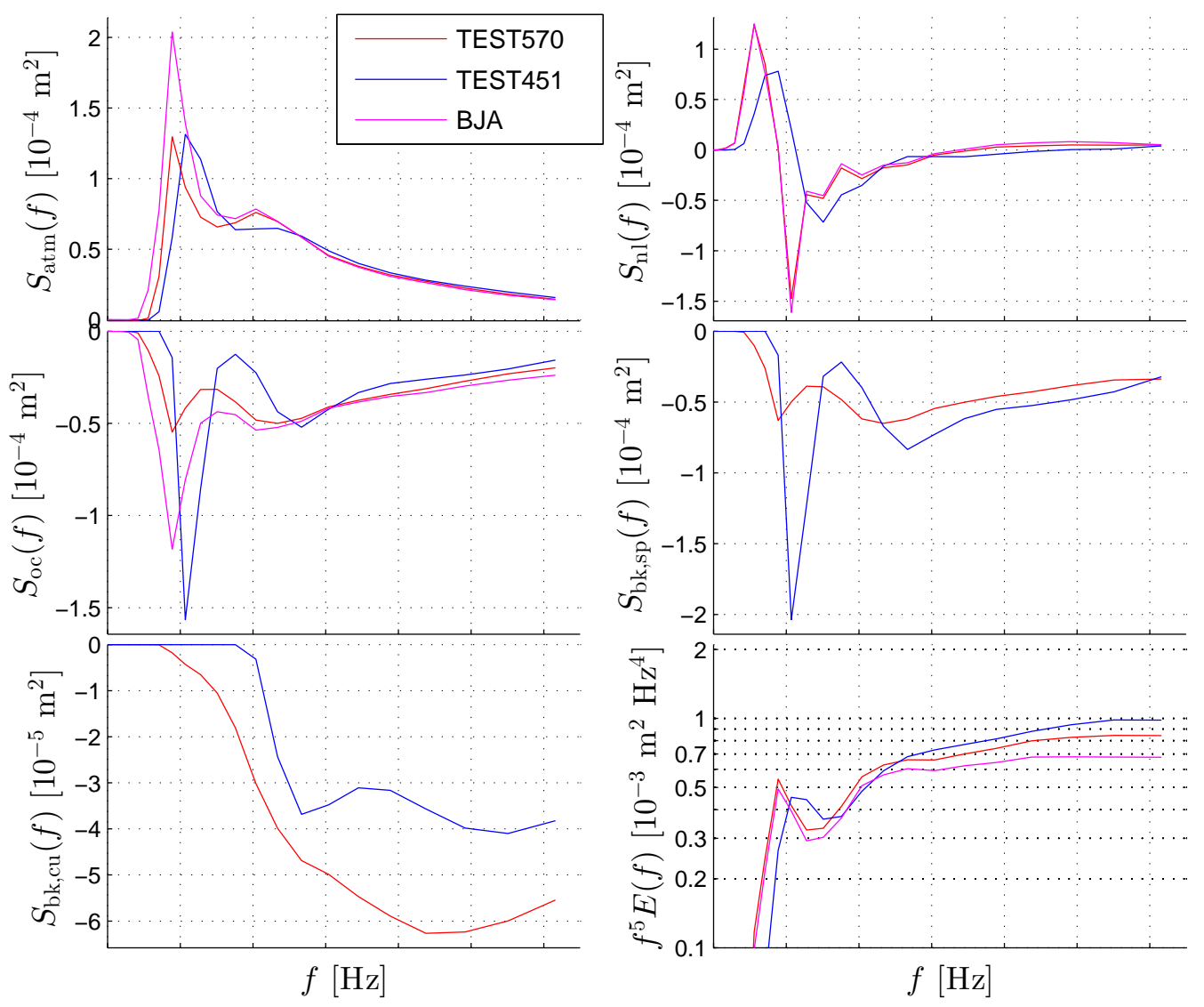

Figure 3: Source terms for TEST570, TEST451 and BJA parameterizations using DIA for non-linear interactions after 8 hours of run. The considered model is a uniform infinite deep ocean with a uniform $10 \mathrm{~ms}^{-1}$ wind, starting from rest. 

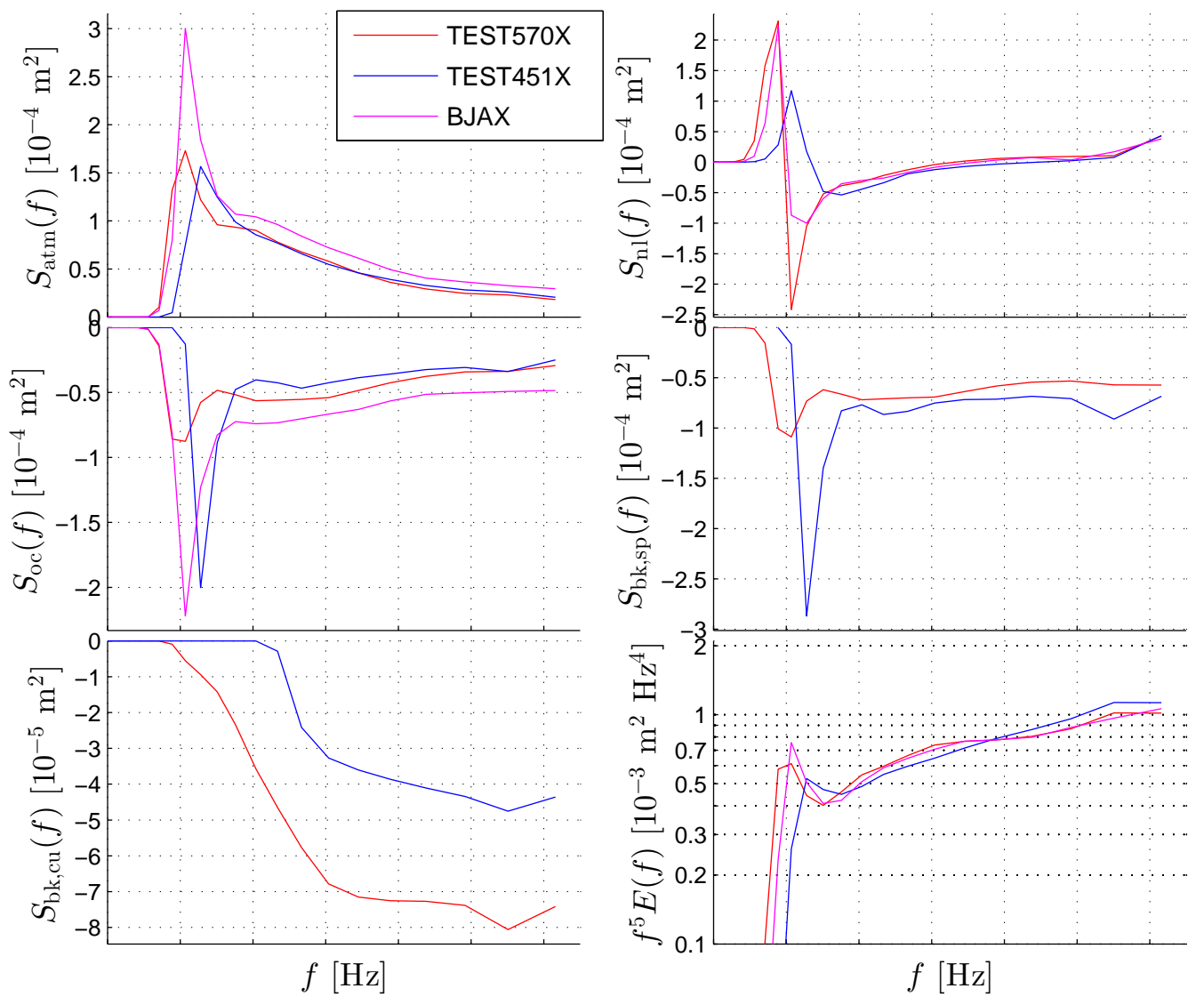

Figure 4: Source terms after 8 hours of run for TEST570X, TEST451X and BJAX parameterizations using XNL for non-linear interactions. The considered model is a uniform infinite deep ocean with a uniform $10 \mathrm{~ms}^{-1}$ wind, starting from rest. 

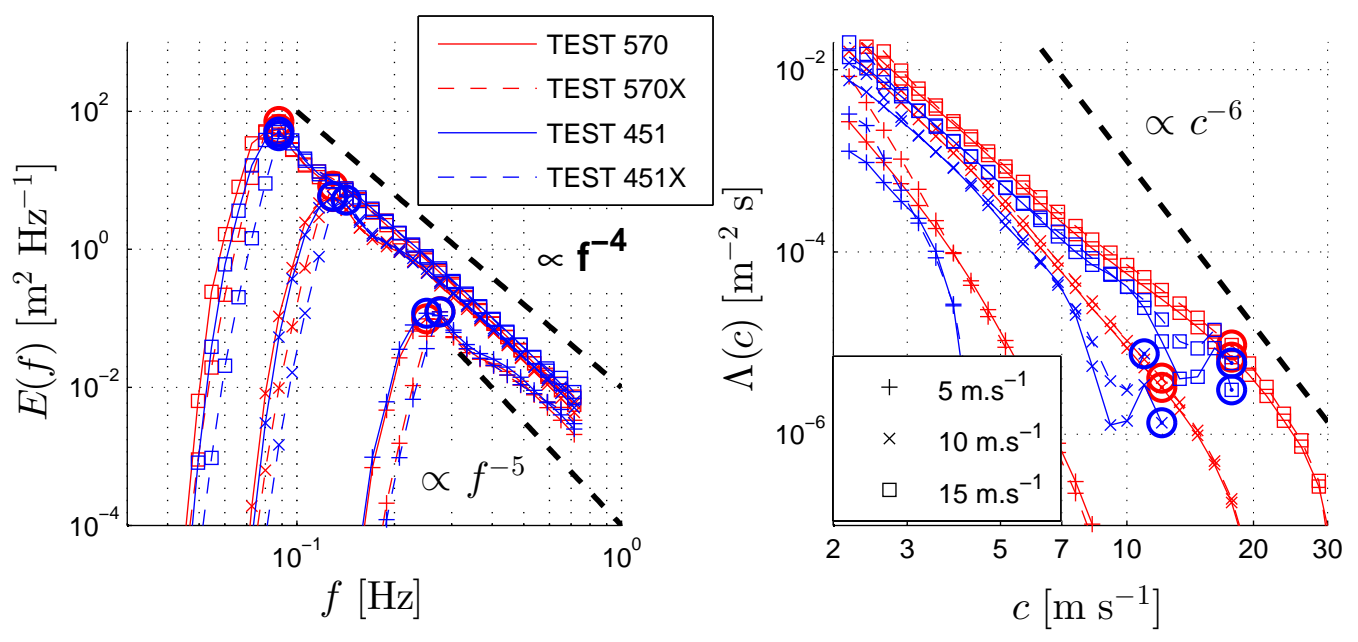

Figure 5: Spectra (left) and direction-integrated breaking crest length distribution (right) obtained with TEST570 and TEST451 parameterizations for a uniform infinite deep ocean after 3 days of run, when $C_{\mathrm{p}} / U_{10}>1.2$, with $U_{10}=5,10$, and $15 \mathrm{~m} \mathrm{~s}^{-1}$. Energy peaks are marked by circles.

\begin{tabular}{|l|c|c|c|c|c|c|c|}
\hline Parameters & WWATCH var. & namelist & TEST441b & TEST451 & TEST500 & TEST510 & TEST570 \\
\hline$\beta_{\max }[1]$ & BETAMAX & SIN4 & 1.52 & 1.52 & 1.52 & 1.52 & $\mathbf{1 . 5 0}$ \\
$s_{7}$ [Eq. A.2] & SWELLF7 & SIN4 & $\mathbf{0 . 0}$ & $2.310^{6}$ & $\mathbf{0 . 0}$ & $2.310^{6}$ & $2.310^{6}$ \\
$B_{\mathrm{dw}}[2]$ & SDSBCK & SDS4 & 0 & 0 & $\mathbf{0 . 1 8 5}$ & $\mathbf{0 . 1 8 5}$ & $\mathbf{0 . 1 8 5}$ \\
& SDSC1 & SDS4 & 0 & 0 & $\mathbf{1}$ & $\mathbf{1}$ & 0 \\
$\kappa[$ Eq. 14] & WHITECAPWIDTH & SDS4 & 0.3 & 0.3 & 0.3 & 0.3 & $\mathbf{0 . 1 8}$ \\
\hline
\end{tabular}

Table B.1: Wave model settings for parameterizations discussed in the paper. TEST510 is the updated version of TEST500 (Filipot and Ardhuin, 2012) including minor swell dissipation modification (Appendix A). Bold values are non default values, which need to be reset via the SIN4 and SDS4 namelist (see manual of WAVEWATCH III ${ }^{\circledR}$ ) to switch from the default parameterization (TEST451) to another. [1], see Ardhuin et al. (2010). [2], see Filipot and Ardhuin (2012). 


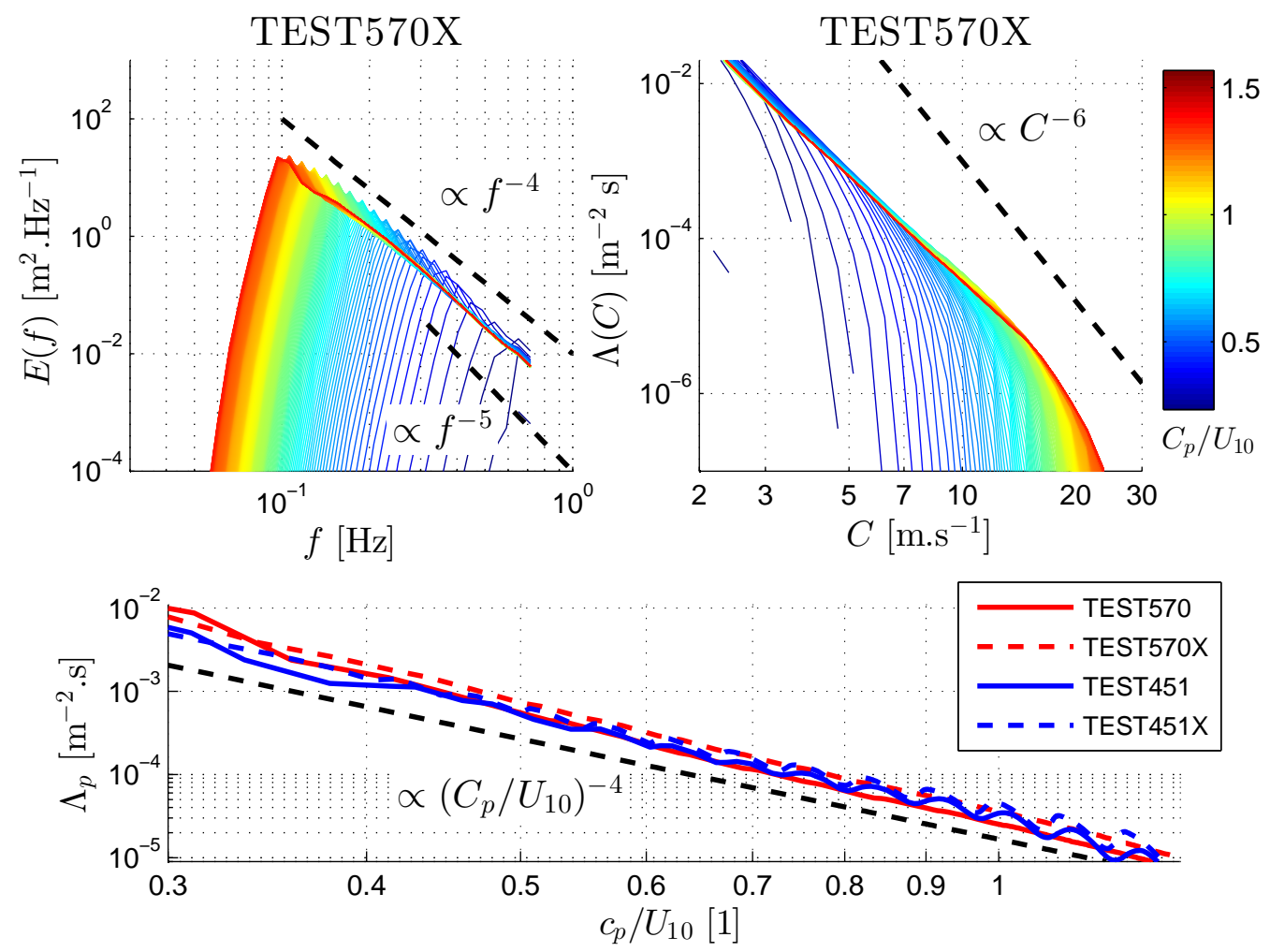

Figure 6: Top: Evolution of spectra (left) and direction-integrated breaking crest length distribution (right) for TEST570 (XNL) with increasing wave age (colours), for $U_{10}=$ $12 \mathrm{~m} \mathrm{~s}^{-1}$. Bottom: Evolution of $\Lambda\left(C_{\mathrm{p}}\right)$ as function of $C_{\mathrm{p}} / U_{10}$, with TEST570 and TEST451 parameterizations 

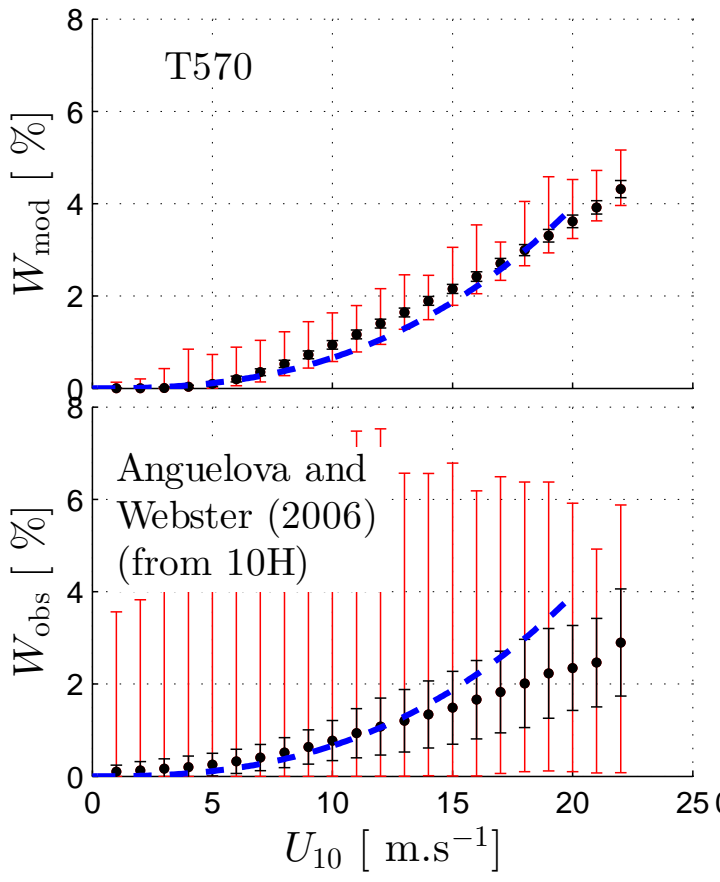

$\mathrm{T} 451$
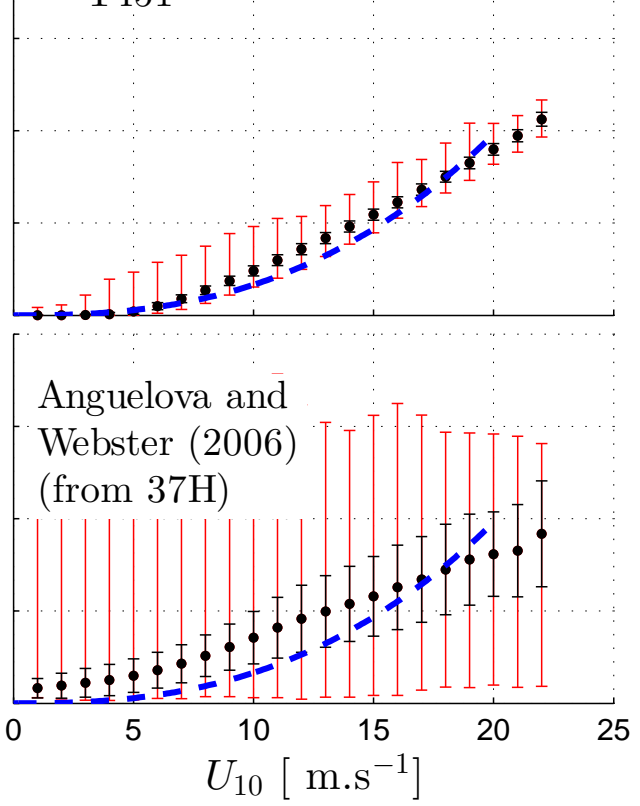

Figure 7: Mean values of $W$ binned under the WindSat track as a function of $U_{10}$ for new parameterization (TEST570) and modified Ardhuin et al. (2010)'s parameterization (TEST451) compared to March 2006 satellite observations by Anguelova et al. (2009). Wind used for binning is the collocated CFSR data, which is independent of the WindSat data until September 2008. Red bars represent minimum and maximum values, black bars are the standard deviations and the blue line represents the empirical fit by Monahan and Woolf (1989). 


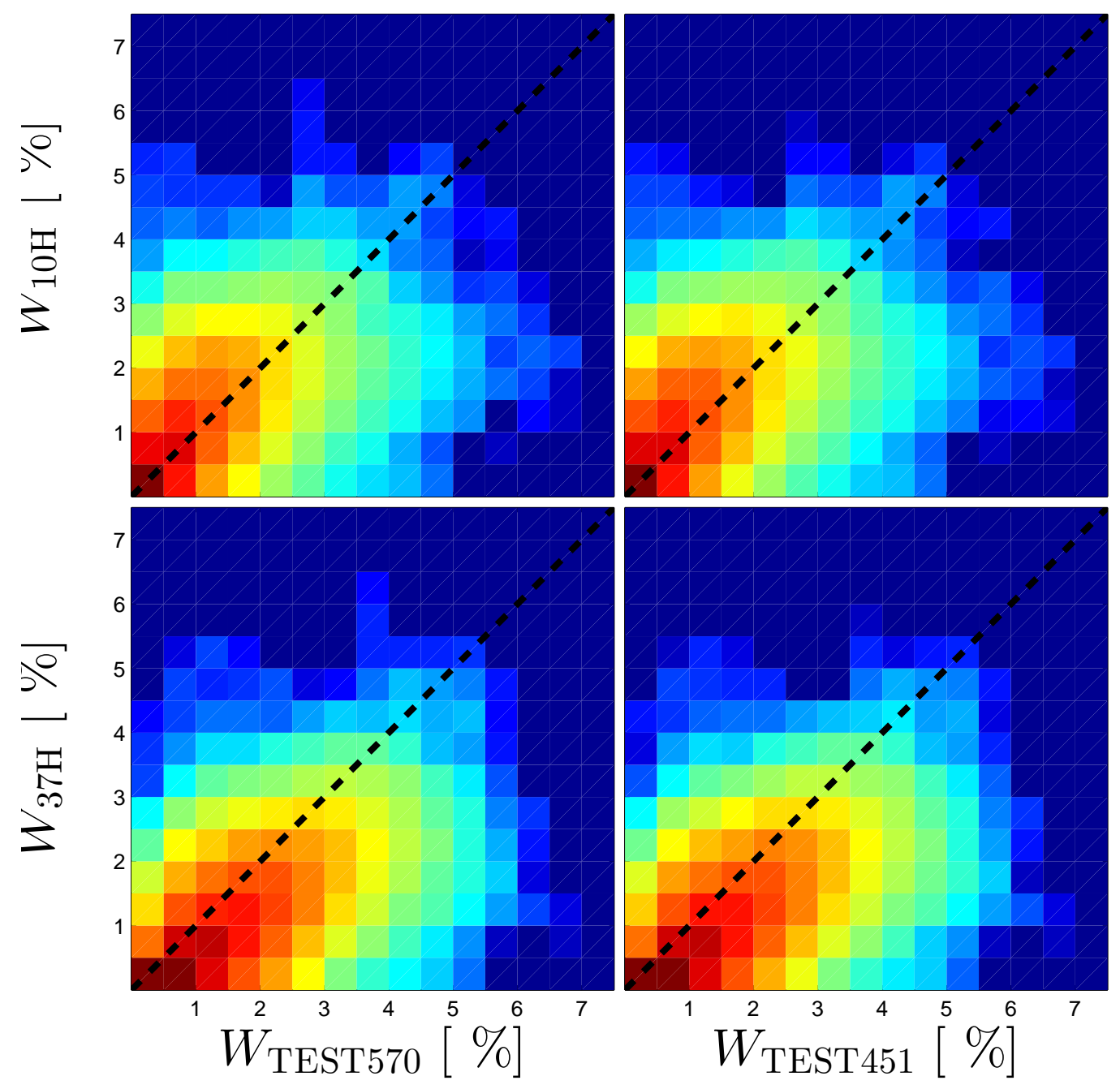

Figure 8: Q-Q plot of WCC given by TEST570 and TEST451 and satellite observations (Anguelova et al., 2009) on March 2006. Compared values are collocated under WindSat swath. Colours give the values of $\log \left(N_{\text {val }}\right)$. 
TEST570

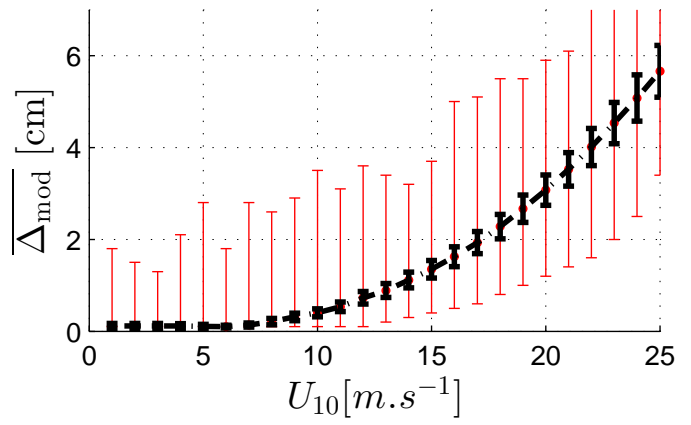

TEST451

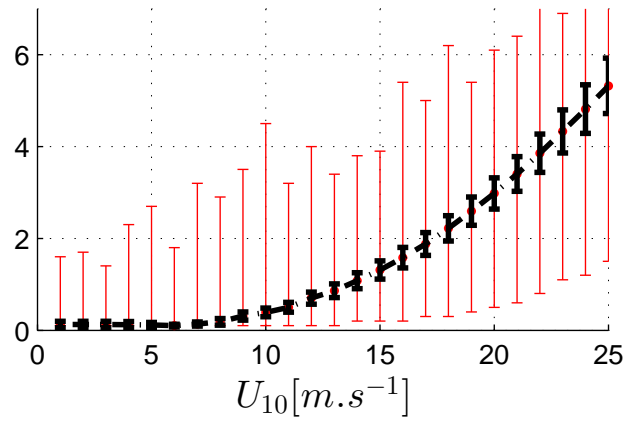

Figure 9: Annual average (2006) of mean foam thickness for TEST570 and TEST451 parameterizations. 

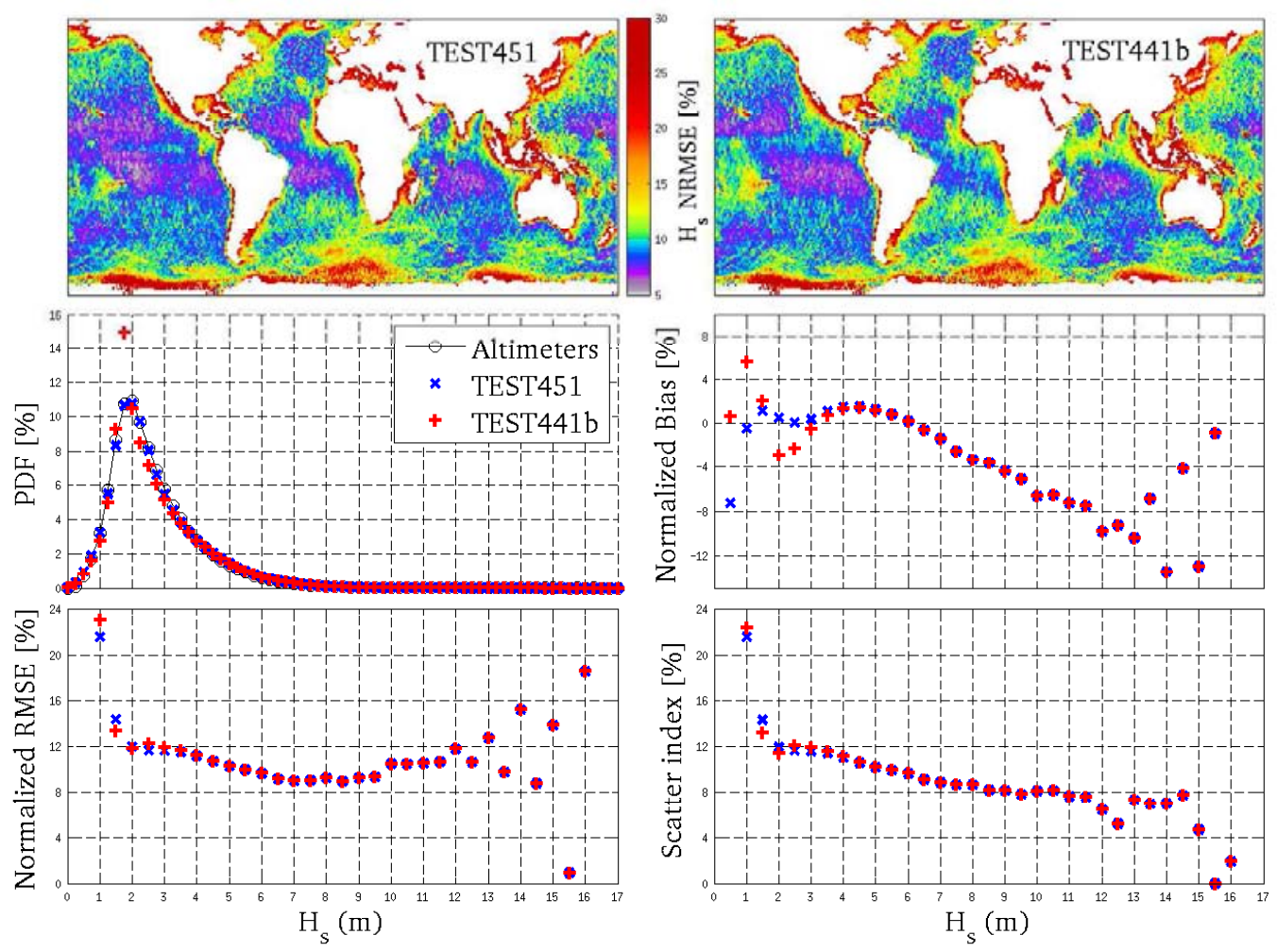

Figure A.10: Top: Global NRMS Error for parameterizations TEST441b (left) and TEST451 (right). Middle: Comparison of PDF of wave heights (left) and Normalized bias vs wave height (right). Bottom: Comparison of Normalized RMS Error (left) and Scatter Index vs wave height (right). 


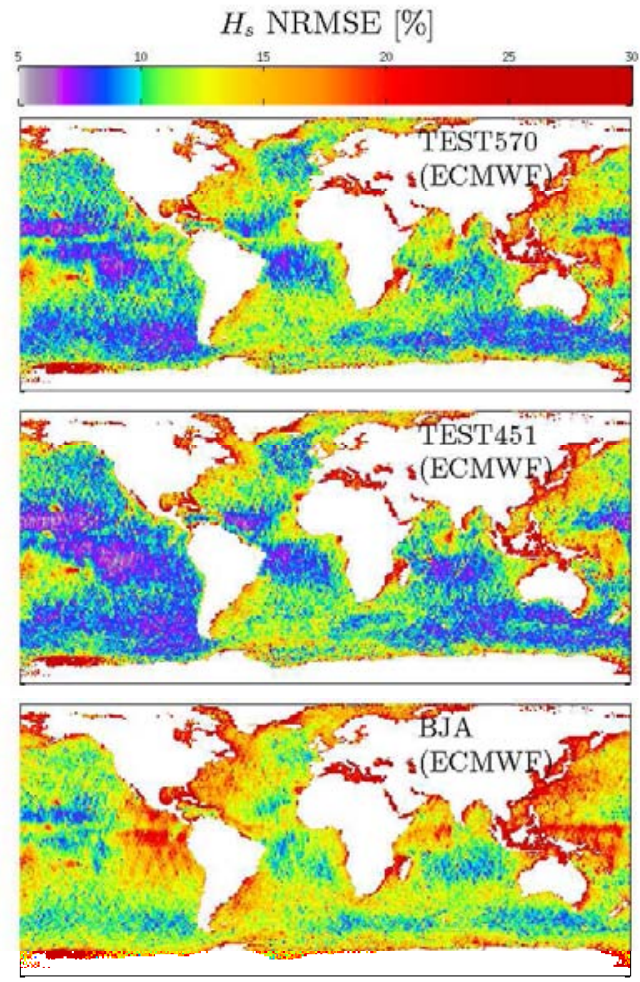

Figure C.11: Normalized RMS Error for new parameterization TEST570 compared to TEST451 (Ardhuin et al., 2010) and BJA (Bidlot et al., 2005) parameterizations for whole 2006 year. In all three cases the model is driven by ECMWF operational wind analyses. 


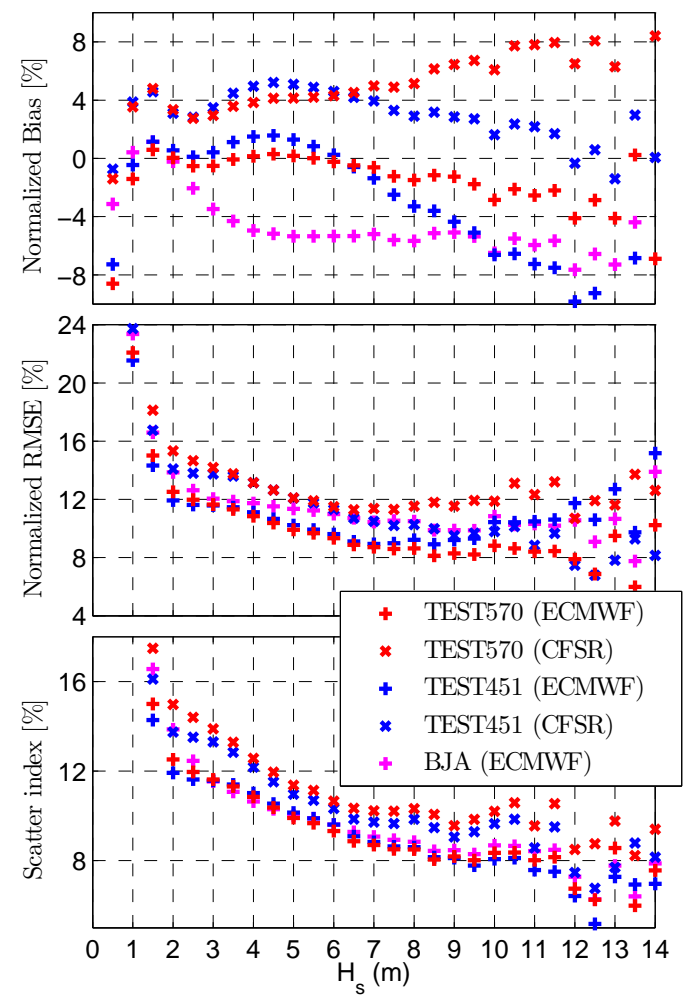

Figure C.12: Normalized Bias, RMS Error and Scatter Index on $H_{s}$ for new parameterization TEST570 compared to TEST451 and BJA parameterizations. 

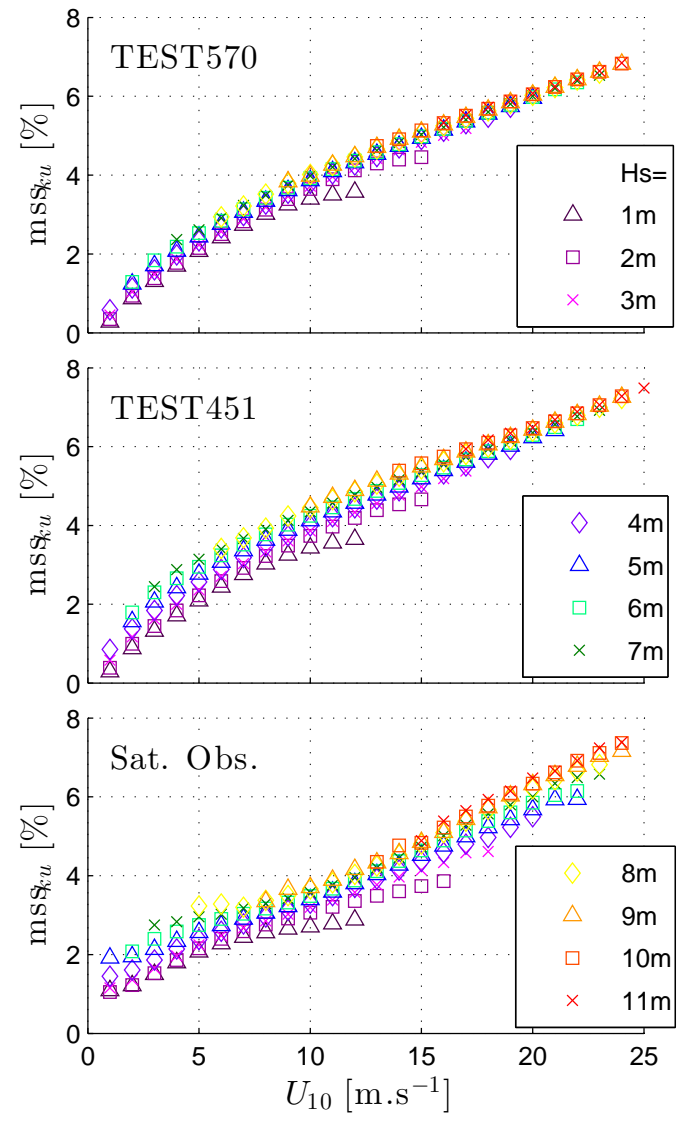

Figure C.13: Mean values of mss $_{\mathrm{ku}}$ binned as a function of $H_{s}$ (x-axis) and $U_{10}$ (y-axis) for TEST570 and TEST451 parameterizations and satellite observations. 

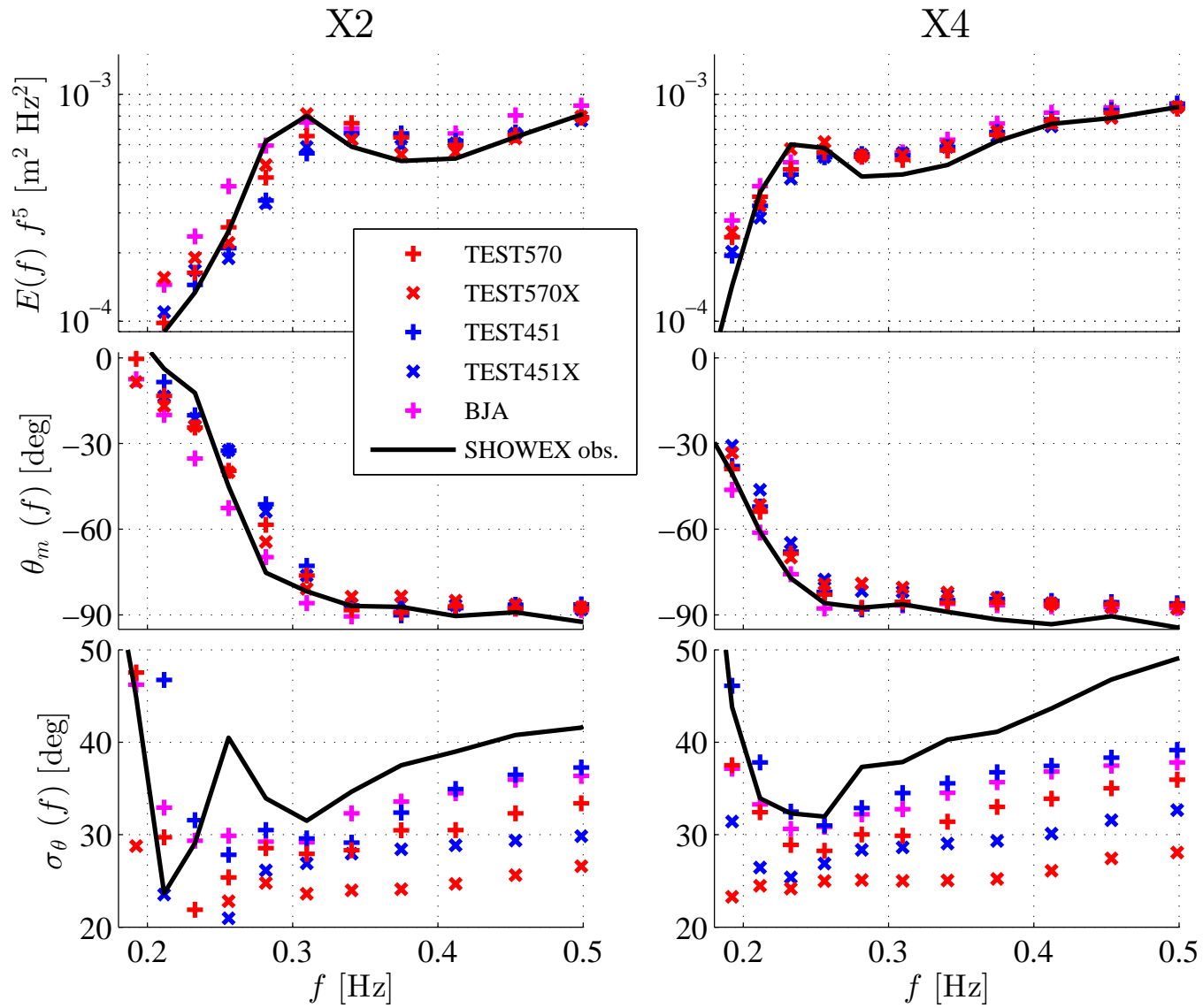

Figure C.14: Wave spectra (top panels), mean direction (middle panels) and directional spread (bottom panels) on 3 November 1999 at buoy X2 and X4, averaged over the time window 12:00-17:00 EST, from observations and model runs with T451, TEST510 and T570 parameterizations. The swell is excluded due to the frequency range used in the figure. 